\title{
Périls et promesses de l'abondance microbienne
}

Natures nouvelles et écosystèmes modèles, du fromage artisanal aux mers extraterrestres

\section{Heather Paxson et Stefan Helmreich}

Traducteur : Valentine Leÿs

\section{OpenEdition}

Journals

Édition électronique

URL : https://journals.openedition.org/tc/8647

DOI : $10.4000 /$ tc. 8647

ISSN : $1952-420 X$

Éditeur

Éditions de l'EHESS

\section{Édition imprimée}

Date de publication : 18 décembre 2017

Pagination : 248-285

ISBN : 978-2-7132-2708-0

ISSN : 0248-6016

\section{Référence électronique}

Heather Paxson et Stefan Helmreich, «Périls et promesses de l'abondance microbienne », Techniques \& Culture [En ligne], 68 | 2017, mis en ligne le 18 décembre 2019, consulté le 29 septembre 2022. URL : http://journals.openedition.org/tc/8647; DOI : https://doi.org/10.4000/tc.8647 


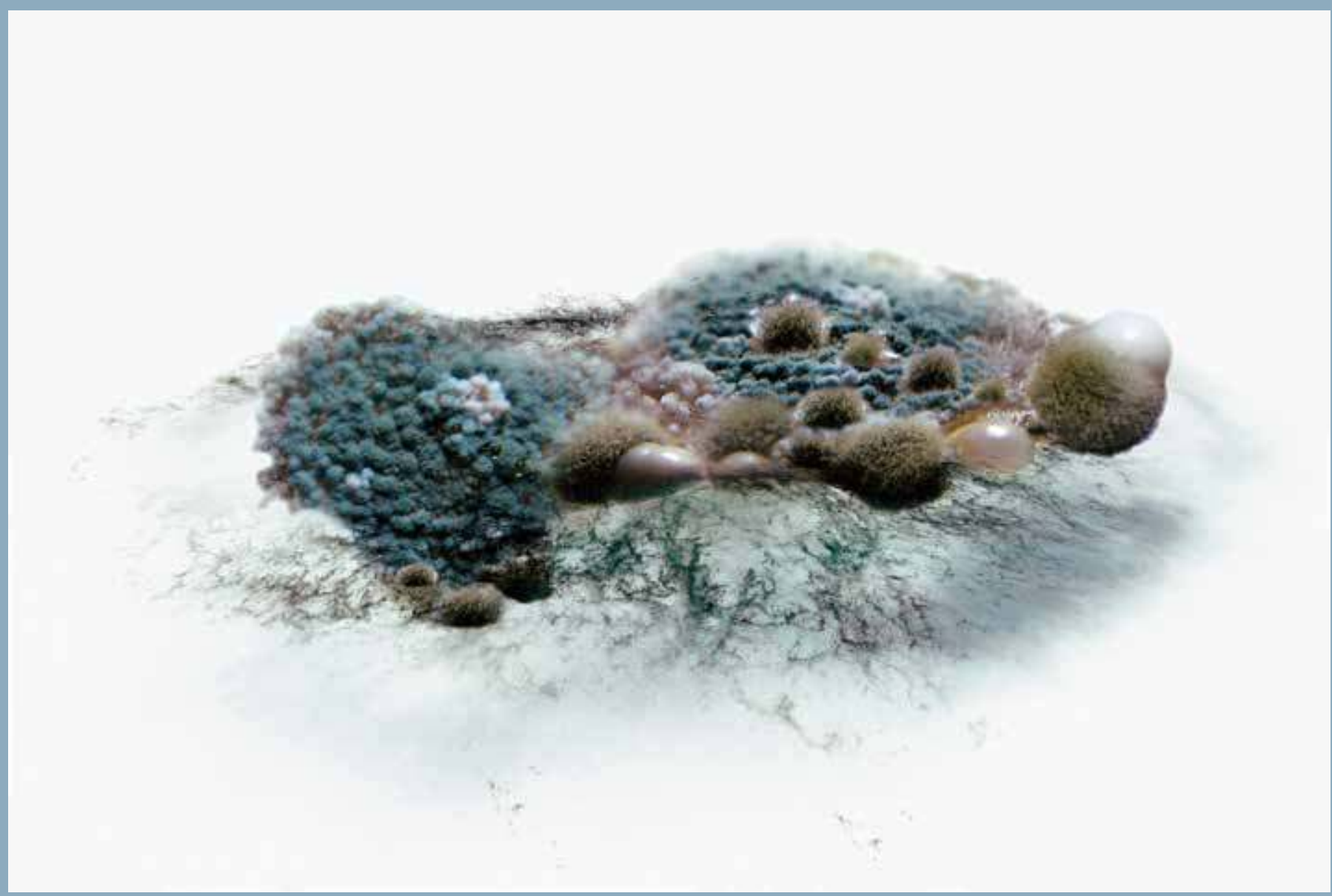




\title{
Périls et promesses de l'abondance microbienne
}

\section{Natures nouvelles et écosystèmes modèles, du fromage artisanal aux mers extraterrestres}

\begin{abstract}
«Les microbes étaient déjà présents des milliards d'années avant les humains, et continueront certainement de prospérer bien après notre disparition. Cette idée est en fait des plus rassurantes, car nous ne pourrions pas survivre sans eux. Ils sont les recycleurs de la planète, invisibles travailleurs qui assurent la perpétuation de la vie, et partenaires silencieux de nos corps [...] Désormais, ami lecteur, vous regarderez d'un œeil nouveau [...] chaque bouchée de fromage.
\end{abstract}

Certains pensent que les extrêmophiles peuvent nous aider à comprendre les formes de vies qui pourraient exister sur des planètes froides, chaudes ou acides, dans les tréfonds de l'espace. »

Jeanette Farell, Invisible Allies: Microbes that Shape Our Lives (2005: 143-144).

On pourrait les appeler les microbes du millénaire. Dans de nombreux domaines, scientifiques ou populaires, en particulier aux États-Unis, on a vu émerger dans le début des années 2000 une utilisation des microbes comme modèles et véhicules de discours sur les nouvelles politiques alimentaires, l'avenir de l'écologie et de la biomédecine, et même sur l'étude d'hypothétiques formes de vie dans d'autres mondes. Alors même que la nature biologique au sens large du terme est considérée comme menacée par un certain nombre de processus anthropogènes (changement climatique, dégradation agro-industrielle, destruction des forêts tropicales, surpêche), dans le même temps la nature biologique au sens le plus étroit du terme -autrement dit, la vie microbienne-fait l'objet d'une attention nouvelle. Les écologistes s'intéressent depuis peu à la dimension microbienne des écosystèmes, tandis que les microbiologistes commencent à regarder au-delà de leurs bouillons de culture pour examiner la manière dont les communautés microbiennes fonctionnent dans les environnements que constituent le sol, l'océan ou l'air, au sein desquels ces dernières ajustent le climat, atténuent la pollution et parfois même fournissent la matière première pour la création de nouvelles biotechnologies comme les biocarburants (voir 
Pottage 2006). À l'heure où les microbiologistes ont recours au séquençage génétique pour caractériser l'infiniment petit, le corps humain peut désormais être lu comme un consortium de microbes: le projet Microbiome humain (Human Microbioma Project) a entrepris de caractériser les $90 \%$ de cellules de notre corps qui sont de nature microbienne (Nerlich \& Hellsten 2009), avec l'objectif d'exploiter ce que les NIH (instituts nationaux de la santé) désignent comme « un domaine présentant un fort potentiel pour la santé humaine ${ }^{1} »$. Dans toutes sortes de domaines, les microbes - ou mieux, les écosystèmes microbiens-apparaissent désormais comme une promesse d'abondance et de potentialités futures.

Le champ des études des sciences et techniques (Science and Technology Studies, ou STS) a pris acte de ce moment microbien: on a analysé l'apparition de nouveaux systèmes de classification des micro-organismes (Helmreich 2003, O’Malley \& Dupré 2007, Sommerlund 2006), l'émergence d'une pensée biopolitique qui prend en compte les processus à médiation microbienne comme l'infection et la digestion ${ }^{2}$, et le succès inattendu d'agences travaillant avec les organismes bactériens, fongiques et viraux, à la fois en laboratoire et sur le terrain (Helmreich 2009, Hird 2009, Ingram 2011, Schrader 2010). La nature microbienne, qu'elle se manifeste sous la forme d'organismes monocellulaires ou d'assemblages cellulaires, matérialise et modélise un monde dans lequel on voit s'abolir les frontières taxonomiques, métaboliques et ontogénétiques entre d'une part les humains, animaux, plantes, fungi et protistes, et de l'autre les bactéries et archées qui font ou non partie de leur entourage (Sagan 2011). Le tournant microbien emprunté ces dernières années par la biologie marque à notre sens l'avènement d'une nouvelle conception ascendante de la «nature ». Cette nature pullulerait d'opérations organiques se déployant à des échelles échappant à la perception humaine, et serait vis-à-vis des identités biologiques et des communautés humaines, animales et fongiques à la fois indépendante et étroitement imbriquée, indispensable et parfois destructrice (voir McFall-Ngai et al. 2013) ${ }^{3}$. Les microbes ne sont plus désormais associés, comme le faisait à la fin du xxe siècle la conception réductionniste du génome avec ses promesses de clonage à l'identique, à l'« ère du contrôle biologique (Franklin 2007, Wilmut et al. 2001) : au contraire, ils tendent vers une biologie non déterminée et pleine de potentialités qui reste à explorer.

Cet article examinera ces nouveaux modèles en documentant la manière dont, dans les représentations contemporaines de la nature biotique et les pratiques qui y sont associées, l'abondance microbienne a évolué pour devenir, plutôt que le signal d'un péril, celui d'une promesse. Nous étudierons deux cas: l'un issu du domaine de l'alimentation, dans lequel les microbes représentent une nature intimement liée, voire intégrée, à celle de l'humain; l'autre associé à la recherche de formes de vie extraterrestres, dans laquelle les microbes suggèrent l'existence d'une nature biotique très éloignée de notre nature terrienne. Dans chacun de ces cas, l'abondance microbienne est analysée à la fois à l'aune de sa singularité et à celle de sa généralité, c'est-à-dire de son omniprésence et de son étendue, dans le quotidien comme dans le lointain.

Notre premier cas concerne les politiques alimentaires, dans lesquelles la vie microbienne attire depuis peu l'attention des législateurs, des producteurs, des commerçants et des consommateurs (Nestle 2003). Depuis Louis Pasteur, les microbes véhiculés par les aliments sont très largement considérés par les services d'hygiène, les législateurs chargés de la sécurité 
alimentaire et les consommateurs comme des agents pathogènes. Pourtant, depuis une dizaine d'années, les microbes qui permettent de produire des aliments fermentés comestibles et bons pour la santé font l'objet d'un véritable regain d'intérêt, voire même de popularité (Katz 2003, 2012, Pollan, 2013). En partant du travail de terrain de l'une des coauteurs de cet article, Heather Paxson (2013), nous nous concentrerons sur la vie microbienne que l'on rencontre dans le fromage artisanal. Les éléments microbiens contenus dans les fromages artisanaux se sont récemment trouvés au coeur des débats entre législateurs et acteurs du secteur, sur la question de savoir comment concilier les risques microbiens potentiellement associés à la fabrication artisanale de fromage, en particulier celle de fromage au lait cru (non pasteurisé), avec le plaisir gustatif qu'apporte la consommation de ce produit (Kurtz et al. 2013, Neuman 2011, Paxson 2008, 2013) ${ }^{4}$. Tandis qu'en Amérique du Nord le sort réservé par la législation aux fromages au lait cru reste incertain, ce débat a placé la constitution microbienne du fromage sur le devant de la scène: ce produit est désormais souvent cité pour illustrer la manière dont les microbes prêtent aux aliments fermentés des qualités uniques, les rendant à la fois sains et savoureux. Si les microbes sont présents partout dans le fromage et à sa surface, seuls certains d'entre eux sont pathogènes pour l'humain et seules certaines souches, espèces ou communautés sont considérées comme des modèles illustrant les bienfaits gustatifs ou sanitaires de ce produit pour l'humain ${ }^{5}$. Même lorsque l'on adhère à la promesse des bienfaits microbiens, il reste nécessaire de garder à distance le péril que représentent les microbes.

Notre second cas nous conduit hors de ce monde: nous examinerons les spéculations sur la vie microbienne sur d'autres planètes, dans l'environnement extraterrestre étudié par l'astrobiologie qui est l'étude de la vie telle qu'elle est susceptible d'exister ailleurs dans l'univers. À partir du travail de terrain de l'autre coauteur de cet article, Stefan Helmreich, nous examinerons comment l'existence potentielle de microbes dans d'autres mondes, après avoir suscité la crainte d'éventuelles contaminations interplanétaires, nourrit aujourd'hui des spéculations sur l'existence de formes de vie extraterrestre. D'après les recherches de l'astrobiologie sur les limites du vivant, si les microbes sont présents partout autour de nous, seules certaines souches, espèces ou communautés constituent des modèles capables de nous aider à mieux connaître les propriétés générales ou universelles du vivant.

Qu'ils se rapportent au fromage ou à la vie extraterrestre, nos exemples ont en commun de susciter des débats dans lesquels la vie microbienne révèle de nouvelles potentialités encore latentes dans la nature organique et biotique. Cependant, les microbes ne suffisent pas à eux seuls à ouvrir de telles potentialités: c'est en se matérialisant dans des pratiques culturelles, sociales, politiques et scientifiques que les microbes ont tendance à recadrer et à reconfigurer ces pratiques sous des formes inattendues - une idée qu'avançait déjà Bruno Latour dans Les microbes: guerre et paix (1988 [1984]), et qui peut être adaptée à notre époque contemporaine. Depuis le xixe siècle pasteurien sur lequel écrit Latour, les microbes sont représentés différemment: comme des organismes non plus seulement effrayants, mais aussi désirables. Les microbes sont également pensés sous un angle nouveau: non seulement comme des souches distinctes, mais aussi comme des communautés, des entités qui existent au sein d'écosystèmes divers. 
C'est cette approche relationnelle qui rend désormais les microbes attractifs et fait d'eux des objets intéressants à penser et à utiliser. En effet, pour les scientifiques, les microbes sont pleins de potentiel inconnu et non encore caractérisé, tout en se prêtant aussi aux projets culturels. Les microbes sont devenus des gages de potentiel (voir Taussig et al. 2013). Tout comme les organismes modèles, les microbes sont des objets «à la fois naturels et artificiels» (Ankeny \& Leonelli 2011: 315) 6 . Bien entendu, cette lecture des microbes à partir du binôme nature/culture s'inscrit parfaitement dans l'ethos moderniste, où la nature se conçoit comme à la fois innée et construite (voir Rabinow 1992). Cependant, les microbes se distinguent aussi des autres organismes modèles au sens où ils sont souvent mobilisés par référence à leur caractère relationnel et à leur ouverture -vis-à-vis des autres microbes, des autres organismes et des humains. Les microbes constituent de bons candidats pour former ce que certains de nos interlocuteurs scientifiques appelleraient des écosystèmes modèles.

Nos deux études de cas présentent des chercheurs qui ont entrepris de défricher l'abondance microbienne pour identifier et modéliser à la fois l'unique et l'universel. L'unique et l'universel jouent le rôle de la figure et du fond, et ces deux pôles s'inversent régulièrement lorsque l'on s'efforce de déchiffrer les microbes. Ainsi, certains producteurs de fromages s'intéressent au caractère unique des microbes (est-ce qu'une souche ou une communauté microbienne donnée n'existe qu'en un seul endroit?): il s'agit de comprendre si des microbes récemment identifiés contribuent à la singularité d'un fromage, en lui conférant des qualités spécifiques à un lieu et à une méthode de fabrication. Dans le même temps, les astrobiologistes s'intéressent à l'universalité (est-ce qu'un certain type de vie microbienne peut se rencontrer n'importe où?): il s'agit de savoir si des microbes récemment identifiés affichent des qualités générales communes à tout le vivant. En procédant ainsi par bonds entre l'unique et l'universel, il devient possible d'exploiter les écosystèmes microbiens dans des projets de plus en plus ambitieux, qui visent à la fois à naturaliser des pratiques culturelles et à culturaliser la nature.

À l'heure où les intellectuels annoncent la «fin de la nature», pour reprendre les mots du journaliste scientifique Bill McKibben (2006 [1989]), de tels écosystèmes offrent aux scientifiques comme au grand public l'espoir nouveau d'une nature non encore domestiquée ou connue: une nature future. Les microbes et les communautés microbiennes représentent en ce sens des biologies modèles au sens canonique du terme, tel que les définissent les chercheurs en STS: des entités, souvent standardisées, qui peuvent être examinées pour définir des propriétés biotiques durables ou inattendues, ou soumises à des tests afin de dégager des généralités en partant des organismes les plus simples pour aller jusqu'aux plus complexes (voir Ankeny \& Leonelli 2011, Creager 2002, Kelty 2012, Kohler 1994, Rader 2004, Ramsden 2011). Mais il s'agit aussi de modèles relationnels dans le sens prescriptif du terme: des indices de ce que pourraient ou devraient être les relations écologiques entre les humains et les autres organismes. Ces deux interprétations du terme sont liées entre elles: si l'on repense les microbes comme des éléments appartenant à des écosystèmes, comme des entités qui facilitent et alimentent de nouvelles relations, on cerne ainsi le corps et l'esprit des promesses et des prescriptions que comportent les discours sur les natures microbiennes. 


\section{Matérialité, microbes et modèles}

Notre intérêt pour les nombreux avatars du microbe ne doit pas être lu comme une affirmation de l'importance de la matérialité de ces derniers. Nous tenons au contraire à nous distancier de manière programmatique de certaines nouvelles formes de matérialisme qui se diffusent depuis peu dans les sciences.

Depuis l'appel de Jane Bennett dans Vibrant Matter (2010) à reconnaître le pouvoir vital propre à des matières comme les ordures, le métal et le pétrole, jusqu'à l'intérêt de plus en plus répandu dans les STS pour l'« ontologie ${ }^{7}$, en passant par les tentatives de la «théorie de l'affect» (Massumi 1996, Sedgwick 2003, Whatmore 2002) de théoriser un champ de ressenti et d'action présocial (parfois purement mental) ${ }^{8}$, certains spécialistes des STS ont invoqué les concepts de matérialité et d'ontologie dans une tentative de naviguer, de Charybde en Scylla, entre d'une part les écueils d'un réalisme dépassé, et d'autre part ceux de la construction sociale (voir aussi Alaimo 2010). Certains domaines des STS ont entrepris de résoudre l'énigme de la matérialité telle que la définit avec pertinence Judith Butler dans Ces corps qui comptent (2009 [1993]), ou bien d'adapter l'injonction faite par Annemarie Mol (2002) de cataloguer les multiples ontologies qui se solidifient autour de l'expérience corporelle ${ }^{9}$, ou encore d'approfondir le concept de «réalisme agenciel» introduit par Karen Barad (2007). On se trouve ainsi circonscrit dans un espace qui, pour productif qu'il soit sur le plan analytique, peut aussi s'avérer dangereux. Cet espace est productif, car il peut permettre une rupture avec les certitudes du déterminisme social, dont le programme fort en sociologie des sciences (Strong Programme in the Sociology of Knowledge) représente un exemple canonique. Productif aussi parce qu'il permet de montrer que les phénomènes émergent dans la pratique ${ }^{10}$. Mais il peut aussi être dangereux: en effet, les nouvelles tactiques matérialistes ont tendance à universaliser des énoncés métaphysiques sur la nature de la «matière», et aussi parfois à prendre pour argent comptant les idées formulées par la science comme des vérités -évolution que nous considérons comme une régression pour les STS.

Examinons par exemple la citation de Bennett (2004: 349) selon laquelle «le matérialisme chose-pouvoir représente la matérialité comme un flux protéiforme d'énergie-matière ». Cet énoncé présuppose que le lexique de la physique offrirait le meilleur moyen de décrire le monde matériel. Bennett précise clairement que ses tentatives d'invoquer un monde au-delà de la signification humaine sont spéculatives: elle conviendrait donc aisément que sa description pose un certain nombre de difficultés analytiques. Une approche issue des STS ou de l'histoire des sciences poursuivrait le questionnement, en demandant comment l'auteur en est venue à utiliser le terme d'«énergie-matière », emprunté à une ontologie particulière née du développement au XIX ${ }^{e}$ siècle de la science électromagnétique et de la thermodynamique.

On retrouve une perspective similaire à celle de Bennett dans New Materialisms: Ontology, Agency, and Politics (Coole \& Frost 2010). Les directrices de l'ouvrage Diana Coole et Samantha Frost exhortent le lecteur à prendre part à « une réorientation ontologique qui fait écho à l'évolution des sciences naturelles, et est dans une certaine mesure informée par cette dernière» 
(ibid.: 6-7). Cette réorientation intègre la description par Einstein du monde atomique comme une zone de "constante émergence, de fluctuation, et de déplacement des nouds de charge » (ibid. : 11), tout en épousant la nouvelle conception en biologie des organismes comme «produits d'interactions complexes entre des gênes et une série d'autres facteurs comme les hormones, les stimuli neurochimiques, l'alimentation et les conditions environnementales» (ibid. : 17). Ce type de «nouveau matérialisme» intègre la science faite, plutôt que la science en action (Latour 1987), comme fondement de la matérialité ${ }^{11}$. Comme le souligne Tim Ingold (2007) dans son article « Materials against materiality», il existe également un risque épistémologique à énoncer des généralités sur la «matière» sans prendre en compte ni sa diversité (physique, chimique et biologique entre autres) ni les propriétés historiquement actualisées d'objets comme les roches, les arbres ou les microbes (voir aussi Ingold 2012). Ingold s'inquiète du fait que le nouveau matérialisme soit très souvent «exposé dans un langage d'un hermétisme grotesque, pour décrire le rapport entre la matérialité et diverses autres qualités tout aussi impénétrables, comme l'agentivité (agency), l'intentionnalité, la fonctionnalité, la socialité, la spatialité, la sémiose, la spiritualité et l'incarnation» (Ingold 2007: 2). De toute évidence il n'est pas souhaitable d'abandonner entièrement les abstractions, puisqu'elles sont elles aussi des choses, mais à force de n’appréhender la «matérialité » qu'au moyen de noms abstraits, on devient incapable d'observer la matière dans la pratique. Steve Woolgar et Javier Lezaun ont récemment synthétisé cette idée dans un article pour la revue Social Studies of Science: "Tout comme le "contexte" et les termes qui y sont apparentés, la "matérialité" doit être comprise comme le résultat contingent d'un ensemble de pratiques, plutôt que comme un socle de réalité prêt à être illuminé par l'investigation ontologique.» (Woolgar \& Lezaun 2013: 326).

Du fait de leur statut d'entités biologiques non-humaines et non-animales, il n'est guère surprenant que les microbes soient devenus un matériau d'étude pour les STS. En effet, oscillant vis-à-vis des activités humaines entre détachement et étroite association, ceux-ci apparaissent comme les actants idéaux: rendus visibles par les activités humaines de signification (microscopes, taxonomies), ils n'ont aucune conscience de ces pratiques ${ }^{12}$. La vie microbienne a inspiré les savants à repenser l'incarnation (Hird 2009), l'agentivité (Ingram 2011) et le temps (Schrader 2010). Ces réflexions ont à la fois préfiguré et réajusté les aspirations récentes à développer une «ethnographie multi-espèces » (Kirksey \& Helmreich 2010) qui intègre à l'analyse sociale les corps et les actions des animaux, des plantes, des fungi et des microbes. Toutefois, il est important de ne pas oublier qu'un être microbien est incapable de donner son avis. C'est pourquoi lorsque Myra Hird (2009) écrit dans The Origins of Sociable Life, une ethnographie sociologique d'un laboratoire de microbiologie, qu'avant Pasteur les bactéries étaient déjà « des actants à part entière ( (ibid. : 35) et que «les actants dépassent toujours la compréhension que l'on obtient d'eux de manière indirecte» (ibid.: 36), elle donne l'impression de traiter les microbes comme une classe naturelle forcément pérenne. Lorsque Hird suggère de «trouver un terrain d'entente avec les microbes» (ibid. : 54), elle apporte une ouverture d'esprit tout à fait salutaire à des phénomènes qui n’ont pas encore été entièrement capturés par la représentation. Cependant, lorsqu'elle rapporte les propos des microbiologistes qui lui ont servi d'informateurs, 
Hird prend souvent leurs propos au pied de la lettre. Elle écrit par exemple: «Les bactéries ont continué de développer des capacités d'ingénierie complexes, pour s'adapter à des contraintes environnementales défavorables. » (Ibid. : 46). La philosophe Maureen O’Malley décrit cet écueil dans sa note de lecture sur l'ouvrage de Hird:

«En n’abordant pas la manière dont la science est faite, ainsi que le caractère perpétuellement révisable et contestable des résultats obtenus en microbiologie, l'auteur nous laisse l'impression qu'il existe une source de connaissance incontestable et universellement acceptée, à laquelle nous pouvons tous boire.» (O’Malley 2011 : 129).

Pour reprendre les mots de notre collègue Cristina Grasseni, cette approche devrait être qualifiée, plutôt que de «nouveau matérialisme», de «nouveau réductionnisme ${ }^{13}$ ».

Dans l'étude qui suit, nous ne traiterons donc pas les microbes comme des émissaires de la vérité toute nue, mais plutôt - en conversation avec nos interlocuteurs du champ de l'ethnographie-comme des écosystèmes modèles. Si «les organismes modèles sont toujours utilisés pour représenter un groupe d'organismes plus large» (Ankeny \& Leonelli 2011 : 318), les communautés microbiennes considérées comme des écosystèmes modèles sont, comme l'explique Hannah Landecker, « des micro-scènes sur lesquelles des modes de vie microbiens font irruption dans la vie humaine ${ }^{14} »$. Les microbes sont utilisés pour signifier des mondes et des socialités biologiques plus vastes, des périls et des promesses plus importants, dans des mondes imaginaires à venir. L'enjeu pour les STS est de comprendre comment réfléchir précisément à la manière dont les choses et les humains s'associent pour créer des objets et des agentivités (agencies). Nous devons donc continuer dans nos travaux à résister à ce que Donna Haraway (1989: 8) appelle la «tentation» du «chant des sirènes scientifiques».

Cet essai a pour objectif d'apporter une contribution aux débats autour des organismes modèles dans le champ des STS. Il s'agira de montrer que, en particulier lorsqu'il s'agit de microbes, les scientifiques pensent de plus en plus souvent en termes d'écosystèmes, et de suggérer que cette pensée s'accompagne de visées explicitement normatives. En pensant les écosystèmes modèles, on considère ces modèles non seulement comme des représentants, des normes ou des objets expérimentaux, mais aussi comme des exemples moraux: des modèles qui ne sont pas seulement descriptifs, mais aussi prescriptifs. Si, comme l'écrivent Ankeny et Leonelli (2011 : 318), « les organismes modèles sont des modèles d'organismes entiers, intacts », le caractère «entier» attribué aux microbes dans les exemples que nous discuterons ci-après est attaché à des systèmes «entiers »- des écosystèmes - qui englobent aussi les projets culturels et les intérêts des humains. Les microbes permettent aux artisans fromagers et à leurs clients, mais aussi aux astrobiologistes et à leur public de penser et de mesurer le caractère plus ou moins unique ou universel de leurs projets gastronomiques et astronomiques. Ils nous offrent ainsi non seulement des écosystèmes modèles mais des écologies modèles, c'est-à-dire des tentatives de penser le monde. 


\section{Le cas du fromage artisanal}

\section{Cru, périlleux et plein de promesses}

D’un point de vue microbiologique, les fromages, aliments périssables, sont des écosystèmes composés de bactéries, de levures et de moisissures fonctionnant au sein d'environnements lactiques entretenus par une intervention humaine. De tels écosystèmes microbiens peuvent être propices au développement d'agents pathogènes humains. Ainsi, le 21 octobre 2010, des agents fédéraux firent fermer la fromagerie familiale Estrella dans l'État de Washington, qui dut suspendre la vente de ses fromages au lait cru qui avaient gagné de nombreux prix. Un juge fédéral ordonna la saisie après que la famille Estrella ait refusé de rappeler la totalité de ses fromages, au vu de preuves présentées par des fonctionnaires de la US Food and Drug Administration (FDA) montrant la «présence persistante » dans une de leurs caves d'affinage de Listeria monocytogenes (une bactérie qui peut causer la listériose, associée à un risque de fausse couche et de mort à la naissance lorsqu'elle est ingérée par une femme enceinte). Toujours dans l'État de Washington, en décembre 2010, des agents fédéraux ont exigé de la fromagère Sally Jackson qu'elle modernise l'équipement qu'elle utilisait dans sa ferme depuis trente ans. Comme elle n'avait pas les moyens d'effectuer ces rénovations, Jackson prit sa retraite après que son fromage au lait cru ait été associé à huit cas d'infections à E. coli.

Pour la FDA, ces cas (ainsi que d'autres survenus par la suite) justifient une révision de la réglementation sur les fromages au lait cru aux États-Unis. Depuis 1949, date à laquelle une épidémie de typhoïde fut causée par un cheddar au lait cru infecté par la bactérie Salmonella, la FDA exige que le fromage, pour être légalement commercialisable, ait été soit fabriqué à partir de lait pasteurisé, soit affiné pendant au moins soixante jours à une température supérieure à $1,7^{\circ} \mathrm{C}$. Les règlements aux États-Unis reposent sur l'idée que le contrôle pathogène s'effectue au choix par l'un des deux moyens suivants: soit en pasteurisant le lait afin de supprimer d'éventuels pathogènes avant la fabrication du fromage, soit en réduisant l'humidité et en augmentant l'acidité du fromage grâce au processus d'affinage, qui contribue à créer un environnement inhospitalier pour les pathogènes comme E. coli et Salmonella. Cependant, du point de vue de la sécurité, la règle des soixante jours apparaît comme de plus en plus obsolète, notamment parce que d'autres pathogènes particulièrement virulents et parfois mortels ont été depuis 1949 caractérisés ou associés à des maladies d'origine alimentaire, comme Listeria monocytogenes et l'E. coli enterohémorragique O157: H7. L'avenir législatif de la règle des soixante jours d'affinage, et donc de la fabrication de fromages au lait cru dans le pays, reste encore incertain. En 2011, David Acheson, «ancien commissaire adjoint de la FDA», a déclaré à un correspondant de la National Public Radio (NPR) que si l'affinage des fromages au lait cru s'avérait insuffisant pour tuer les bactéries pathogènes, «alors de toute évidence la prochaine étape serait de rendre la pasteurisation strictement obligatoire» (Standen 2011).

Les autorités régulatrices américaines portent depuis peu une attention accrue sur les fromages au lait cru, au moment même où le nombre d'artisans fromagers connaît une croissance 


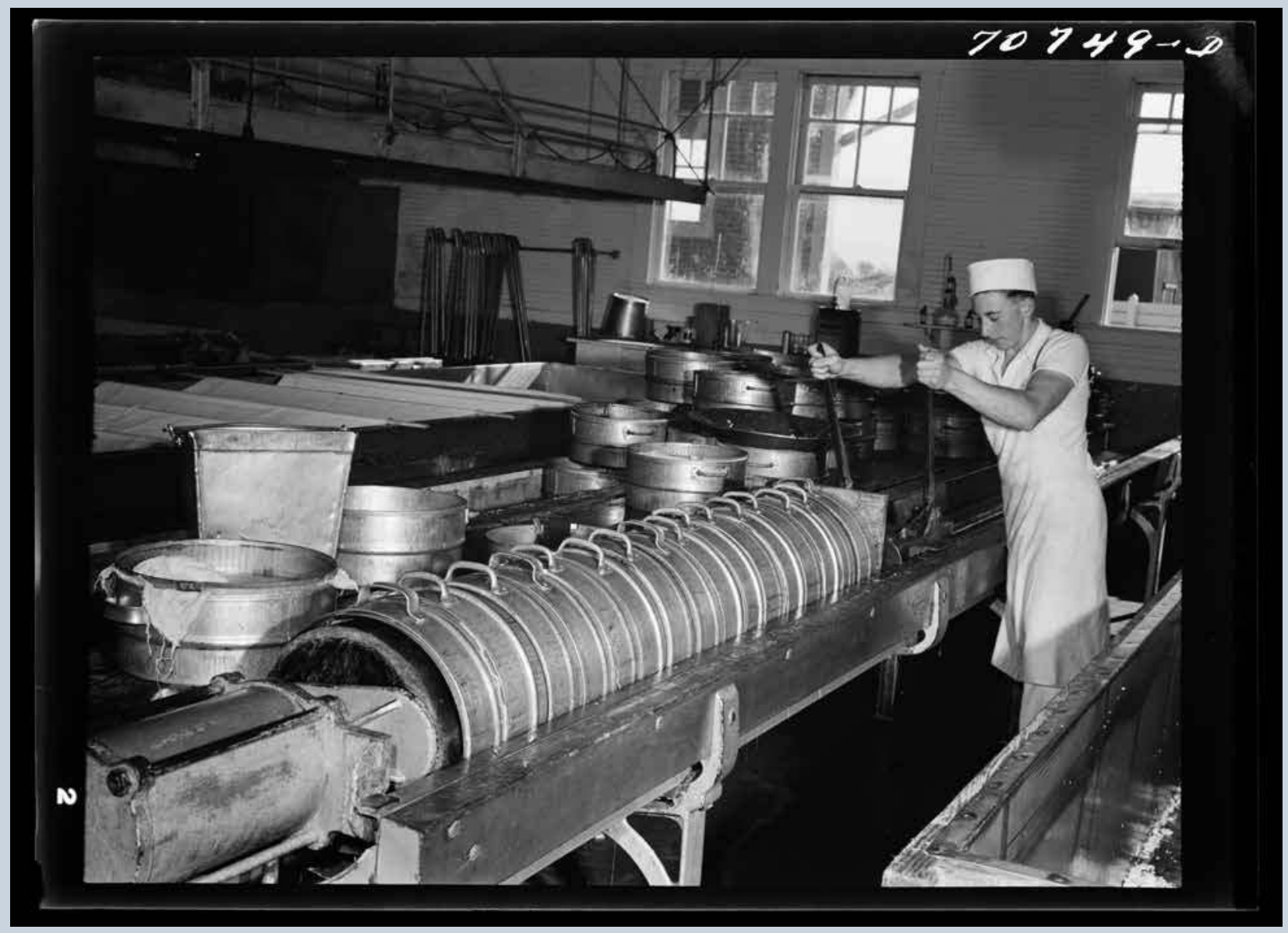

Pression du lait caillé.

Ce processus élimine l'humidité et forme une texture serrée dans le fromage.

Usine de fromage Tillamook, Tillamook, Oregon.

Russell Lee, 1941. 
exponentielle (et certainement du fait de cette croissance) : sur les 450 producteurs actuellement en activité, $50 \%$ environ produisent moins de cinq tonnes de fromage par an, et plus de la moitié travaillent avec du lait cru ${ }^{15}$. Face à un système réglementaire conçu pour l'industrie et déterminé à dompter une nature insoumise en éradiquant par la force les contaminants microbiens (Dunn 2007), on voit émerger un ethos artisanal résolument moderne, qui utilise des partenariats sélectifs avec les organismes microscopiques de notre environnement au service des visées des humains. On pourrait qualifier ces deux régimes hygiéniques opposés de pasteurien et post-pasteurien (voir Paxson 2008, 2013). Là où les pasteuriens voient dans le fromage au lait cru un véritable biohazard et un produit potentiellement infesté de bestioles dangereuses, les post-pasteuriens voient l'inverse: un aliment traditionnel dont la salubrité est garantie par l'action de bons microbes (bactéries, levures et moisissures) capables de supplanter les mauvaises bestioles dans la compétition pour les nutriments du lait.

Pendant la plus grande partie du xxe siècle, pour le grand public, les germes nocifs ont occupé le premier plan dans les perceptions du monde micro-organique dans son entier: sous le régime moderniste et pasteurien de la FDA, les microbes sont représentés comme des éléments périlleux qui doivent être soumis à un contrôle humain (Tomes 1999). Ce péril représente une menace non seulement pour la santé humaine, mais aussi pour l'expansion du marché. En effet, en plus des agents pathogènes comme E. coli et Listeria, on trouve aussi, parmi les microbes indisciplinés des aliments, des bactériophages inoffensifs pour la santé humaine, mais qui empêchent une fermentation correcte et bloquent le développement des odeurs, des saveurs recherchées dans le fromage et les autres aliments fermentés. Étant donné que la pasteurisation tue à peu près tous les micro-organismes d'origine naturelle, pour pouvoir fabriquer du fromage le lait pasteurisé doit être remis en culture, le plus souvent au moyen de souches bactériennes isolées en laboratoire et lyophilisées (ou «levains») qui produisent de l'acide lactique et amorcent la fermentation. Dans les années 1930 aux États-Unis, l'introduction de la pasteurisation dans la fabrication du fromage était motivée autant par le désir d'obtenir des produits plus homogènes et standardisés, de créer des économies d'échelle -autrement dit, par des impératifs de marché - que par des motifs de santé et de sécurité (Latour 1988, McMurry 1995 : 123-124). La pasteurisation a ainsi permis la naissance des fromages industriels et standardisés.

Aujourd'hui, le marché répond à des préoccupations plus diversifiées. De plus en plus de consommateurs recherchent des aliments non standardisés, aux caractéristiques gastronomiques distinctes, dont ils attendent qu'ils soient plus sains tout en soutenant l'agriculture familiale et l'artisanat, plutôt que les géants du secteur agroalimentaire en partie responsables de la dégradation environnementale des terres. Ces consommateurs recherchent des aliments «modèles» autour desquels mettre en place une agriculture revue et corrigée. C'est précisément la qualité qui, dans les fromages au lait cru, provoque les réticences des services d'hygiène -le fait que ces fromages renferment toutes sortes de microbes inconnus-qui rend leur consommation particulièrement désirable pour certains consommateurs. Certains adeptes de ces fromages soutiennent que l'estomac humain digère plus facilement les aliments contenant des probiotiques «naturels», tandis que d'autres mettent en avant leurs qualités gastronomiques (voir 
McCalman \& Gibbons 2009). On lit ainsi sur le blog d'un aficionado : «Le fromage au lait cru a un certain je-ne-sais-quoi. Ses arômes [...] ont quelque chose de plus champêtre, de plus terrien, de plus nuancé [...] et [sont] tout simplement plus vivants ${ }^{16}$.» Des discours post-pasteuriens comme celui-ci représentent la diversité microbienne comme une qualité en soi, comme une source naturelle de bienfaits pour les humains.

Bien qu'opposés au rêve pasteurien de contrôle des microbes, les fantasmes de floraison microbienne des post-pasteuriens ne portent pas sur tous les organismes sans distinction. Nous qualifions d'ailleurs les producteurs de fromages au lait cru de post-pasteuriens plutôt que d'anti-pasteuriens, car ceux-ci reconnaissent les risques d'infection et le rôle de l'hygiène dans leur prévention, mais dépassent le pasteurisme en recrutant de «bons» microbes qui agissent comme des amis et des alliés dans cette mission. S'inscrivant dans un mouvement plus large qui s'oppose à la standardisation industrielle de l'alimentation, les post-pasteuriens considèrent la pasteurisation non pas comme un passage obligé pour la sûreté des fromages, mais comme un rouleau compresseur qui anéantit tous les bienfaits potentiels de l'abondance microbienne (voir Paxson 2008).

Si nous avons reconnu en ouverture de cette partie que les microbes transmis par les aliments continuent de présenter un danger, un aspect de la vague d'intérêt pour les fromages au lait cru nous fascine tout particulièrement: les microbes sont représentés comme les agents d'une nature à la fois non entièrement objectifiée, et considérée comme indissociable de l'activité humaine. Pour cette raison, comme nous le verrons, en cherchant à sauver les cultures microbiennes indigènes de l'homogénéisation industrielle, les producteurs de fromage post-pasteuriens ont peut-être pour objectif de légitimer leurs pratiques de production alimentaire non industrielle. Les microbes sont l'incarnation des possibles: non pas du fait de leur matérialité brute, mais parce qu'ils peuvent être employés pour imaginer, et donc formuler, une conception nouvelle de la science et des politiques alimentaires.

\section{La vie de laboratoire du fromage, ou le fromage comme écosystème modèle}

La microbiologiste Rachel Dutton, titulaire de la chaire Bauer en biologie des systèmes à l'université de Harvard, a commencé, en collaboration avec le mycologiste Ben Wolfe (chercheur postdoctoral), à étudier la croûte superficielle des fromages affinés «naturellement » comme un écosystème microbien modèle, pour comprendre le comportement des microbes vivant au sein de communautés complexes. Lorsqu'elle présente les fondements de son travail à un public d'artisans fromagers, de commerçants et de scientifiques spécialisés dans les produits laitiers lors d'une conférence sur «La Science du fromage artisanal», Dutton (2012) explique que dans le «monde réel », les microbes vivent en communauté et interagissent avec les composantes de leur environnement - les interactions microbiennes sont essentielles pour la «santé» de 
tous les écosystèmes de notre planète. Toutefois, poursuit-elle, les scientifiques ne disposent que de très peu d'informations sur les communautés microbiennes, car ils étudient généralement les microbes isolément en laboratoire. Dutton a introduit des fromages affinés dans son laboratoire, car leurs croûtes constituent des communautés microbiennes densément peuplées d'espèces variées, ce qui en fait des «écosystèmes microbiens modèles». Lorsque Paxson a visité le laboratoire de Dutton, elle y a observé des fromages qui prenaient la forme de boîtes de Petri contenant des cultures de souches de bactéries prélevées de meules de fromages fabriquées par certains des mêmes artisans qu'elle avait interviewés lors de sa recherche de terrain en ethnographie. En étudiant, par le biais du fromage, la manière dont les communautés de bactéries et de fungi interagissent entre elles, Dutton et Wolfe avaient initialement entrepris un projet de recherche en science de la nature qui visait à découvrir «à qui on avait affaire», pour reprendre les mots de Dutton. Le projet relevait plus de l'investigation darwinienne que de la technoscience industrielle. Dutton et Wolfe cherchaient à comprendre ce qu'était (ou qui était) une croûte de fromage, et comment elle était arrivée à cet état, à l'échelle microscopique. Les deux chercheurs ne s'intéressaient que peu à des questions comme l'amélioration de la durée de vie ou la stabilité commerciale du fromage.

Quand Dutton avait dû contacter des fromagers pour les inviter à participer à son étude en laboratoire, elle avait d'abord ressenti une certaine appréhension. En tant que microbiologiste, elle avait l'habitude d'avoir affaire à un public dégoûté par les microbes, et souvent adepte du gel désinfectant pour les mains. Mais cette fois, elle rencontra des artisans curieux de savoir «qui » elle trouverait sur leurs fromages. Les microbiologistes disent souvent pour plaisanter qu'« il y a de tout un peu partout ». De fait, Dutton et Wolfe sont maintenant en train de découvrir que les croûtes de fromage contiennent des microbiotes habituellement associés à des écosystèmes et des lieux incroyablement divers. Leur étude microbiologique préliminaire a reçu une attention considérable dans le monde du fromage. Le numéro du printemps 2011 de la revue Culture: The Word on Cheese publiait une série photographique de huit pages montrant des agrandissements à grande échelle très esthétiques des bactéries et des fungi que le laboratoire avait prélevés dans les croûtes de certains fromages bien connus et cultivés dans des boîtes de Petri (les mêmes échantillons que Paxson avait vus au laboratoire). La légende de l'une de ces photographies explique que «les bactéries et les fungi croissent ensemble pour créer un écosystème microbien. C'est ainsi que les microbes contribuent à créer la saveur, l'odeur et la texture du fromage à mesure qu'il mûrit » (Dutton 2011). La manière précise dont l'abondance microbienne contribue aux arômes spécifiques des fromages est une question complexe que les scientifiques, principalement en Europe, commencent tout juste à soulever. Dutton elle-même précise: «À terme, j'espère découvrir ce que les microbes du fromage peuvent nous enseigner sur les écosystèmes microbiens que l'on rencontre partout dans la nature. » (Ibid. : 81).

Mais tandis que le laboratoire de Dutton cherche à tirer des généralités à partir du cas du fromage, des artisans fromagers comme Andy et Mateo Kehler, dont Dutton et Paxson ont visité en 2011 la ferme de Jasper Hill dans le Vermont, s'intéressent au contraire à son caractère singulier. Le laboratoire de Dutton serait-il capable, se demandent les Kehler, de mettre en évidence 


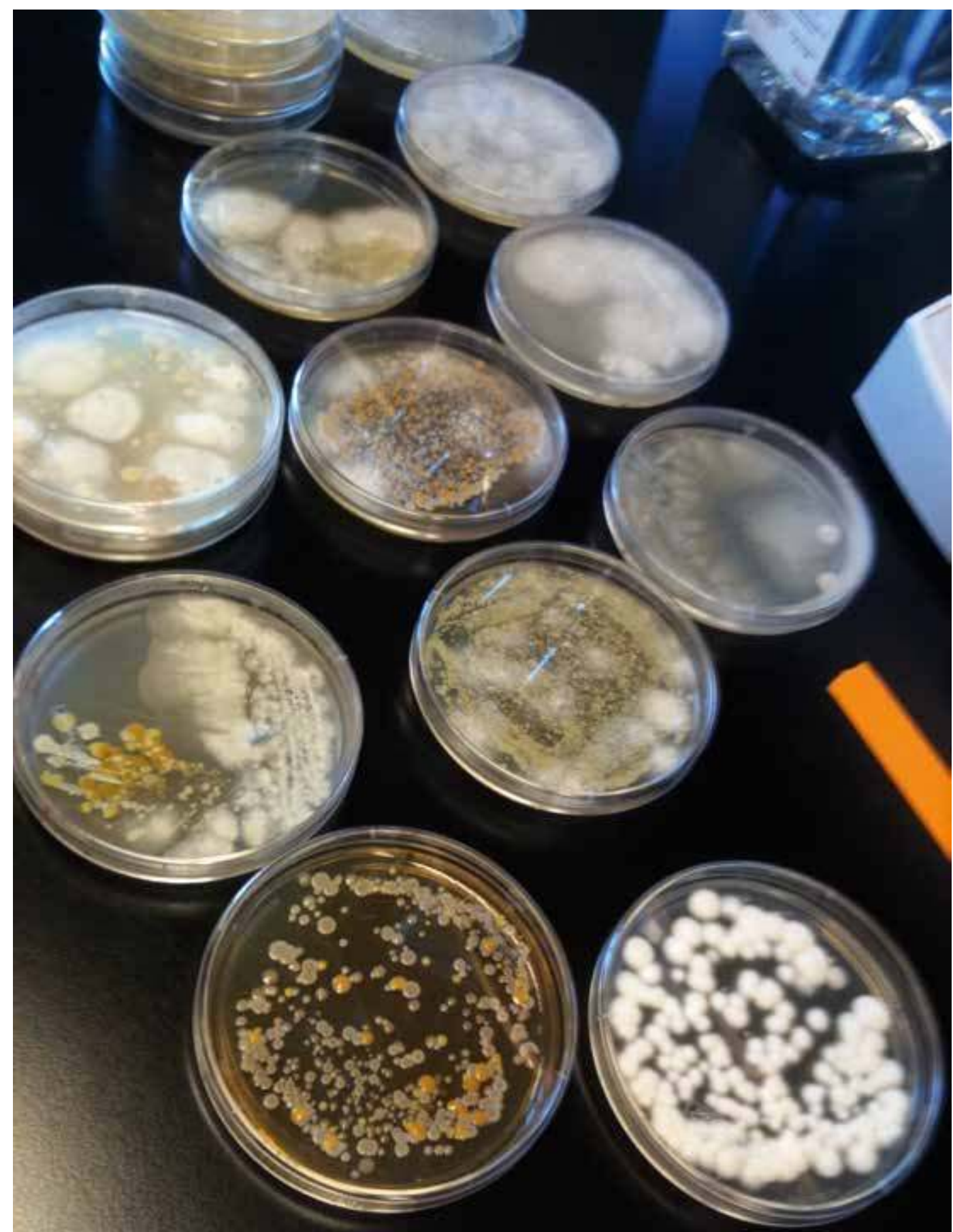

Cultures bactériennes échantillonnées à partir de fromages artisanaux, provenant du laboratoire de Dutton. 
un micro-organisme jusqu'ici jamais caractérisé - ou une communauté microbienne particulière-qui soit indigène, voire même unique, aux écosystèmes que représentent leur ferme et leur fromage? De toute évidence, les Kehler perçoivent dans l'identification de ces microbes un potentiel en termes de marketing, qui leur permettrait de singulariser leur produit dans un marché de niche de plus en plus saturé. Dans le même temps toutefois, la valeur attribuée aux microbes que l'on cherche à identifier réside dans leur éventuelle faculté à incarner un lien tangible, matériel, entre leur fromage et le lieu-l'environnement, la terre, les herbes - dans lequel, ou même à partir duquel, ce fromage est apparu. Les Kehler souhaitent savoir si la découverte de microbes uniques ou de communautés microbiennes singulières pourrait leur permettre d'ancrer le caractère artisanal de leur fromage dans un terroir -terme utilisé habituellement par les viticulteurs pour désigner une conjonction de facteurs liés à la terre, à l'environnement, au climat et aux pratiques traditionnelles, dont on considère qu'elle engendre une distinction de goût (et par là même, une distinction sociale) entre différents produits agricoles. Le fromage pourrait-il être considéré comme un écosystème modèle, non seulement dans le sens scientifique qui intéresse Dutton, mais aussi dans le sens social auquel aspirent les Kehler?

L'idée selon laquelle les microbes seraient à l'origine de la faculté des aliments fermentés de véhiculer et de symboliser le «goût d'un lieu» (taste of place) - pour reprendre les mots qu'utilise l'anthropologue Amy Trubek (2008) pour désigner le terroir - rencontre un succès croissant, dans le monde du fromage comme ailleurs: ainsi, la lettre d'information de la cave d'affinage de Jasper Hill a pour sous-titre: «A Taste of Place». En 2006, un documentaire du Public Broadcasting Service, The Cheese Nun («la religieuse fromagère ») présentait les recherches en microbiologie de Mère Noella Marcellino, qui étudie notamment le champignon de type levure Geotrichum candidum commun à certains types de croûtes de fromage (y compris le Bethlehem, un fromage que produit la religieuse dans son abbaye du Connecticut) à partir du constat que «l'évolution de l'industrie vers une standardisation toujours plus grande des conditions d'inoculation et d'affinage risque de conduire à la perte d'une biodiversité héritée de pratiques empiriques» (Marcellino et al. 2001: 4753). Dans le film, Marcellino explique: «De même que l'on veut sauver certaines espèces d'arbres de la forêt vierge, il faut aussi sauver les microbes propres à certaines régions, car ce sont eux qui contribuent à la saveur et au caractère unique des fromages. » En 2011, le Dairy Business Innovation Center du Wisconsin, un organisme financé par l'État qui propose des conseils techniques pour promouvoir la transformation «à valeur ajoutée» des produits laitiers sur les exploitations agricoles, a organisé un séminaire pour discuter du potentiel de la notion de terroir dans la mise en place d'une appellation protégée. Cette dernière devait être appliquée à un fromage fabriqué dans une région du Sud du Wisconsin, le Driftless, dont la topographie se caractérise par le fait qu'elle a échappé à la glaciation à la fin du Pleistocène. Un consultant technique français, Ivan Larcher, a suggéré lors du séminaire que l'identité des diverses bactéries, levures et moisissures qui entrent en contact avec le lait avant et pendant la fabrication du fromage était

« différente d'une ferme à l'autre, mêmes lorsque celles-ci ne sont éloignées que de quelques kilomètres. Chaque ferme a un spectre qui lui est propre, [...] et le rêve de chaque artisan fromager est de 
développer son propre spectre de bactéries, pour créer une signature qui lui est propre. Ce spectre est directement lié au lieu où vous vivez, et c'est là qu'intervient le concept de terroir qui veut dire que l'on obtient un produit différent selon l'endroit où l'on vit. » (Tenenbaum 2011)

C'est exactement ce qu'a fait un producteur de fromage de la région du Driftless. Quelques années plus tôt, Willi Lehner s'est promené dans les bois derrière sa maison et a «prélevé » des microbes contenus dans la terre. Il a tout simplement fait tremper dans de l'eau des mottes de terre de son jardin pour en isoler les micro-organismes indigènes, a filtré l'eau et l'a mélangée à une solution de saumure. Il a ensuite badigeonné de cette saumure des meules d'un fromage au lait cru de type Harvati pour donner ainsi naissance à l'Earth Schmier, un fromage à la pâte ferme et au goût puissant: en un mot, un fromage «terrien». Dans le cas de l'Earth Schmier, le fromage devient une biotechnologie au service du localisme - ou encore, un écosystème modèle qui exprime une connexion éprouvée dans un lieu.

Cependant, plus on en sait sur la microbiologie du fromage et plus il apparaît que cette ambition d'ancrer des fromages dans un terroir en se fondant sur la spécificité des microbes locaux contredit le caractère mobile des microbes, ou plutôt, leur faculté à être « un peu partout ». Lehner raconte à Paxson que l'idée de récolter des microbes lui est venue après avoir rencontré la fromagère irlandaise Giana Ferguson, qui est connue pour avoir inoculé à son fromage, le Gubbeen, des souches isolées à partir de cultures de laboratoires d'une bactérie jusque-là non identifiée et découverte pour la première fois dans son fromage à croûte lavée: un microbe baptisé Microbacterium gubbeenese. Des quantités infimes de M. gubbeenese ont depuis été identifiées dans des fromages français du même style. Alors que l'on commence à mieux connaître les organismes microbiens qui peuplent les fromages artisanaux, il apparaît que leur caractéristique la plus marquante est leur ubiquité plus que leur singularité: autrement dit, l'image du microbe unique se trouve perturbée par l'ubiquité de la présence microbienne. Lorsque l'on tente de caractériser l'unicité, la singularité ou l'individualité d'un microbe, on se trouve confronté à des conditions et à des connexions écosystémiques qui brouillent les limites de ce que l'on considérait au départ comme un environnement «local». De fait, la force qui préside à la sélection d'une communauté microbienne particulière dans l'écosystème d'une meule de fromage ne saurait être la géographie d'une ferme ou d'une région (les microbes ne connaissent pas les clôtures entre différentes exploitations ni les frontières politiques). L'intervention d'une sélection humaine joue un rôle fondamental, par exemple dans le choix et l'adaptation de recettes particulières. En partant d'un séquençage d'ADN, les recherches de Dutton et Wolfe ont également confirmé les résultats de Marcellino : les communautés microbiennes en présence («à qui on a affaire») dépendent beaucoup plus de la recette ou du type de fromage que du lieu ou de la région géographique. Autrement dit, l'échelle sur laquelle les conditions environnementales favorisent une communauté microbienne plus qu'une autre est plutôt celle d'une meule de fromage que celle d'une région géographique ou politique. La technique est plus déterminante que le climat. Cela n'exclut pas pour autant la notion de terroir; les vignerons français soutiennent depuis longtemps que la «place» du terroir ne se réduit pas à la géographie, mais 
qu'elle résulte de la conjonction de conditions environnementales et de pratiques culturelles présentes en un même lieu pendant plusieurs générations humaines, c'est-à-dire de la mise en place d'un modèle durable de collaboration humain-environnement (Demossier 2011, Teil 2012). Cependant, cette idée complique la compréhension de la notion de «produits locaux» aux États-Unis, où la pratique artisanale est (ré)inventée en permanence, non tant comme une tradition que comme une innovation inédite (Paxson 2010).

En Amérique, l'artisanat exploite le caractère unique des formes nées des mains de l'artisan en prise directe avec la matière. Nous suggérons que c'est cette croyance dans la signature unique née de la pratique artisanale manuelle qui a donné sa forme à l'idée d'une signature microbienne propre à une fromagerie ou à une crémerie. Lors d'une visite des caves de Jasper Hill où les Kehler affinent leurs fromages et ceux d'autres producteurs de la région, Mère Marcellino - dont les recherches en laboratoire ont justement apporté des preuves contredisant la thèse d'une unicité microbienne sui generis - a griffonné sur un mur une remarque qui reflète l'attrait sentimental (et la valeur commerciale) que représente l'idée d'une signature unique: «Le monde du fromage se prépare à goûter les merveilleux fromages affinés dans ces magnifiques caves. J'ai hâte d'en savoir plus sur les fungi que vous cultivez et que l'on ne trouve qu'ici! » La conception écosystémique des microbes entre en tension avec les recherches qui cherchent à identifier des souches distinctes.

Plus récemment, l'idée de cultiver un «terroir microbien» qui permettrait d'apposer sur un aliment fermenté le label d'une «signature gustative» reconnaissable et associée à un lieu particulier a été soutenue par des personnalités comme le chef vedette David Chang. Dans un article pour l'International Journal of Gastronomy and Food Science, Chang et ses associés ont décrit leur travail dans les cuisines du restaurant Momofuku pour développer un produit à base de porc fermenté: le butabushi, doté d'un intense goût umami (savoureux), qui peut être extrait et utilisé en cuisine (Felder et al. 2012). Bien que visiblement enthousiasmés par la «fermentation sauvage» qu'ils sont en train de créer dans leur cuisine (voir Katz 2003), ces chefs commerciaux post-pasteuriens se préoccupent également que leur produit soit propre à la consommation. Ils envoient donc des échantillons de leur écosystème microbien porcin à faire tester au laboratoire de Dutton à Harvard. En plus de rechercher d'éventuels agents pathogènes (l'échantillon n'en contenait aucun), Dutton et Wolfe effectuent un séquençage et une analyse d'ADN pour déterminer si certains fungi spécifiques à l'atmosphère du lieu contribueraient à la spécificité sensorielle du produit. Pour des chefs comme Chang, les microbes semblent donner corps à l'obsession actuelle de la gastronomie pour les produits locaux. Dans un profil du laboratoire de Dutton écrit pour la section Food \& Wine du New York Times, Chang décrit son désir d'inoculer à son miso, à son nuoc-mâm et à son filet mignon fermenté un peu d'ADN de la ville de New York. Chang se demande: «Comment nous y prendre pour faire goûter aux New-yorkais le goût de New York? [...] Ce sont les microbes qui font le terroir. C'est littéralement ce que l'on trouve dans l'air.» (Smith 2012). 


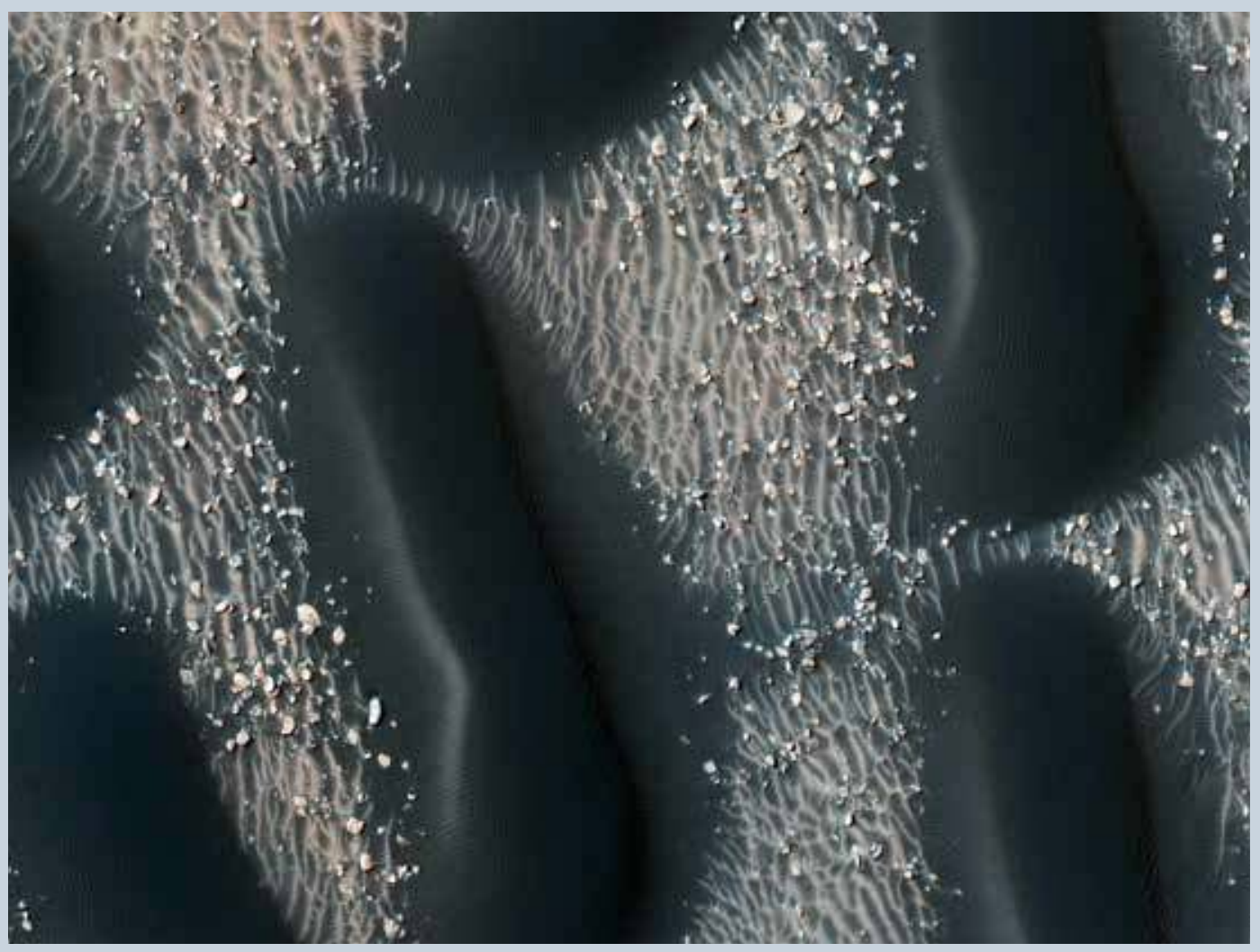

Cette observation depuis une mission de reconnaissance orbitale menée par la Nasa (MRO - Mars Reconnaissance Orbiter) montre le bord d'un champ de dunes sombres sur le sol du cratère Proctor dans les hautes terres du sud de Mars. Les dunes sombres sont composées de sable basaltique qui s'est accumulé au fond du cratère. 
Entre le fromage artisanal et le katsuobushi de Momofuku, la microbiologie appliquée joue depuis peu dans le laboratoire de Dutton un rôle beaucoup plus important que prévu. Que peut-il y avoir de si fascinant pour deux chercheurs en microbiologie dans le potentiel du terroir microbien? Dans un essai sur «le terroir microbien américain » publié en 2012 dans un numéro spécial du journal gastronomique Lucky Peach (dont Chang était pour l'occasion rédacteur en chef invité), Wolfe admet que «pour un microbiologiste, il est tout simplement stupéfiant de voir un chef s'enthousiasmer pour Aspergillus oryzae ou Neurospora sitophila» (Wolfe 2012: 103). Avec les aliments fermentés, les microbiologistes comme Dutton et Wolfe ont trouvé un véhicule qui leur permet de transmettre à un public non initié leur émerveillement devant le monde microbien, un monde où il importe moins de savoir à qui on a affaire que ce que les microbes font ensemble au sein de certaines communautés ou de certains environnements. Le type de matérialité qui intéresse la microbiologie n'est pas la biologie cellulaire des organismes microscopiques, mais la relationalité des écosystèmes microbiens au sein desquels les microbes habitent et transforment d'autres matières organiques, transformant la terre en sol, le lait en fromage et les restes de viande en salami.

Il est impossible, à partir d'une «signature gustative», de remonter jusqu'à l'identité d'un microbe particulier: cette signature est le résultat d'une gestion de la diversité microbienne. Lorsque nous mangeons un fromage ou un salami, ce n'est pas le goût des corps des bactéries ou des champignons que nous sentons mais plutôt, comme l'expliquent des chercheurs comme Dutton, les résidus de la décomposition par le métabolisme microbien des enzymes, des graisses et des glucides contenus dans le lait ou la viande, qui produisent des odeurs et des saveurs particulières. La «signature microbienne, qui serait la trace détectable d'une présence microbienne, n'est donc pas attribuable à des microbes spécifiques mais à des constellations ou des communautés particulières de microbes: c'est le «spectre» dont parle Larcher.

De toute évidence, la manière dont des chercheurs comme Dutton comprennent aujourd'hui les microbes - non plus seulement comme des individus sous un microscope, mais comme des communautés au sein d'écologies depuis peu déchiffrables grâce au séquençage génétique à haut débit - induit également une approche plus «environnementale» de ces microbes à l'état sauvage. Cette approche «environnementale» peut faire apparaître des liens surprenants et parfois révélateurs (sur le plan réel comme sur le plan conceptuel) entre des écosystèmes a priori distincts. Ainsi, pendant que nous menions la présente recherche, nous avons appris avec intérêt que la bactérie prédominante dans un écosystème modèle étudié par le laboratoire de Dutton et issu du Winnimere, un fromage à croûte lavée à l'eau salée produit par la ferme de Jasper Hill, était une Halomonas: un type d'halophile (organisme qui recherche les milieux salins) que l'on rencontre le plus souvent dans les glaces de l'océan Arctique. En 2012, à la conférence «Science of Artisan Cheese », Dutton et Wolfe ont annoncé les résultats préliminaires de leur étude sur les microbes. L'une d'entre elles était que la bactérie Halomonas se trouve dans d'autres fromages à croûte lavée du même style que le Winnimere de Jasper Hill. L'interprétation actuelle de Dutton est que les Halomonas seraient transmises au fromage par le fromager via le sel marin, qui est le principal ingrédient de la saumure servant à «laver» ces fromages. Cette idée semble 
incongrue pour les artisans fromagers, qui considèrent le sel comme un agent antimicrobien plutôt que comme un vecteur microbien. Si l'on considère les microbes d'un point de vue à la fois taxonomique et écologique, les halophiles du Winnimere sont également comparables à certains de ceux que l'on rencontre dans les cheminées hydrothermales, et qui figurent dans les travaux de Helmreich sur l'océanographie microbienne. Ces microbes nous conduisent très loin des pâturages bucoliques, jusqu'au fond des océans et peut-être même jusqu'à des mondes extraterrestres.

\section{Le cas de l'astrobiologie}

\section{Périls et promesses extraterrestres}

L'astrobiologie est l'étude de la vie dans un contexte cosmique et planétaire, sous la perspective des mécanismes physiques et géologiques qui se déroulent sur Terre ou dans d'autres mondes. Cette science est née sous un autre nom: l'exobiologie, fondée vers 1960 par le prix Nobel Joshua Lederberg, un chercheur en génétique bactérienne qui s'inquiétait qu'un vaisseau spatial de retour sur Terre puisse transporter des microbes extraterrestres susceptibles de contaminer la planète. En 1961, le magazine Time spéculait en ces termes dans un article sur les recherches de Lederberg:

«Les envahisseurs qui sont le plus à craindre ne sont pas les petits Vénusiens en soucoupe volante ou les monstres doués d'intelligence qu'imaginent les auteurs de science-fiction. Moins spectaculaires mais plus insidieux, les envahisseurs seront peut-être des micro-organismes extraterrestres, transportés à notre insu sur des vaisseaux spatiaux terriens de retour sur notre planète.» (Cité in Wolfe 2002: 194).

L'exobiologie à sa naissance était une biologie des espèces d'envahisseurs extraterrestres, à des fins de défense contre la nature extraterrestre. Bien que Lederberg fût également attentif à la contamination potentielle d'autres mondes - et, en particulier, de la Lune-par des biotes terriens, l'attention du public, et donc les financements, restèrent dirigés sur la contamination de la Terre par la vie extraterrestre. L'historienne Audra Wolfe note que ces inquiétudes étaient saturées par les représentations de la guerre froide: «Le devoir de l'Amérique de protéger la liberté, si nécessaire par la colonisation d'autres planètes, risquait d'être mis en danger par un ennemi intérieur invisible. » (Wolfe 2002: 185).

La défense biologique de la planète contre des contaminants extraterrestres reste d'actualité pour la National Aeronautics and Space Administration (NASA). En 2005, lors d'un atelier sur l'astrobiologie organisé au Laboratoire de biologie marine de Woods Hole, Massachusetts, nous avons rencontré un chercheur qui détient le titre d'Officier de protection planétaire (Planetary Protection Officer), bien qu'il porte ce titre avec un soupçon d'ironie, puisque ses responsabilités se résument principalement à la tâche très prosaique de stériliser les vaisseaux spatiaux envoyés 
sur Mars. Le grand mythe américain des frontières qui a structuré en grande partie la recherche spatiale dans les années 1960 a laissé place dans les dernières années à des aspirations plus modestes de gestion écologique interplanétaire. Les hypothétiques microbes présents ailleurs dans l'univers font désormais partie d'une nature, d'une diversité qui doit être protégée (on se souviendra peut-être que dans la série de science-fiction Star Trek, la «principale directive» à laquelle les équipiers devaient obéir était de ne pas interférer avec «des formes de vie et des civilisations nouvelles »). La NASA prévoit ainsi d'envoyer un vaisseau spatial sur Europa, une lune glacée de Jupiter que les astrobiologistes considèrent comme une destination prometteuse qui nécessite l'attention des défenseurs de l'environnement:

«Les objectifs pour cette mission en termes de protection planétaire seront d'assurer que le vaisseau spatial ne s'écrase pas accidentellement sur l'une des lunes visées, ce qui risquerait de faire fondre la glace et potentiellement de contaminer l'eau liquide. Les normes de protection planétaire recommandées par le Conseil pour les Études Spatiales du National Research Council pour la mission sur Europa (Preventing the Forward Contamination of Europa) réduiraient la probabilité de contamination des eaux liquides sur Europa par un organisme terrien viable à moins de $10^{-4}$ par mission ${ }^{17}$.»

Cet environnementalisme post-guerre froide embrasse le système solaire tout entier (voir Olson 2010), et avec lui ses microbes non encore découverts.

Avec le lancement officiel de l'Institut d'Astrobiologie de la NASA (NAI) en 1998, l'exobiologie est remise à neuf. L'astrobiologie est définie comme l'étude des origines et de l'évolution de la vie dans un contexte cosmique (voir Des Marais et al. 2003). La microbiologie joue un rôle central, non seulement parce que les organismes unicellulaires apparaissent comme une rencontre extraterrestre bien plus probable que des créatures multicellulaires, mais aussi parce que les recherches de la fin du xxe siècle sur les extrêmophiles, des organismes vivant dans des environnements exceptionnellement chauds, salins ou à très haute pression, ont fait naître de nouvelles spéculations sur les capacités limites des êtres vivants. Les extrêmophiles sont capables de prospérer dans des sites comme les cheminées hydrothermales des profondeurs marines ou les volcans sous-marins, dans des conditions de température et de pression intolérables pour la plupart des organismes connus. Ces organismes sont pendant un temps considérés comme analogues aux premiers terriens unicellulaires, les ancêtres de toute forme de vie. On pense également qu'ils fournissent une indication possible des formes que pourrait prendre la vie dans des mondes lointains, comme les océans extraterrestres d'Europa, la lune de Jupiter, ou bien sur Enceladus, un satellite de Saturne.

Comme nous l'avons vu avec le fromage, les microbes ne sont plus considérés comme des ennemis mais plutôt accueillis comme d'éventuels compagnons pour les projets culturels humains -en l'occurrence, la recherche de formes de vie extraterrestre. La vie extraterrestre n'est plus aujourd'hui associée à l'image d'interlocuteurs civilisés tels que les imaginaient autrefois les programmes américains de recherche d'une intelligence extraterrestre ( Search for Extra-Terrestrial Intelligence »), mais plutôt à celle du minuscule microbe, signe non plus d'une culture mais d'une nature extraterrestre. 
Cette nature, aujourd'hui davantage appréciée que redoutée, est, tout comme la nature du fromage, considérée comme une précieuse source de diversité, d'abondance et de potentialités non encore découvertes ou caractérisées par les humains. Cette croyance est à l'origine en 2010 d'une déclaration étonnante dans le champ de l'astrobiologie: la NAI annonce qu'elle a des raisons de penser que certains microbes seraient capables d'utiliser l'arsenic (au lieu du phosphore) comme l'un des six blocs de construction du vivant (Wolfe-Simon et al. 2010). La germobiologiste Felisa Wolfe-Simon a isolé un microbe dans des sédiments du lac Mono, une étendue d'eau en Californie «hautement alcaline et riche en carbonates, en phosphore, en arsenic et en soufre». Une fois prélevé, ce microbe a été nourri en laboratoire dans un milieu contenant du sucre, des métaux-traces et des vitamines, mais dépourvu de phosphates. En l'absence de toute substance avec laquelle créer l'armature normalement phosphorée de l'ADN, ces microbes auraient, annonce la chercheuse, produit cette armature à partir de l'arsenic. WolfeSimon déclare: «Si nos résultats sont corrects, ce microbe a résolu un défi : celui de vivre sous une forme différente. » Wolfe-Simon et ses collègues suggèrent que ce microbe pourrait fournir un indice de la forme que prendraient d'éventuelles formes de vie extraterrestre.

Ce microbe, la souche GFAJ-1 de la famille de bactéries halophiles Halomonadaceae, devient alors pour un temps la star des «formes de vie» potentielles. On notera que les halophiles étaient aussi présentes dans le fromage modèle de Dutton : ces bactéries étaient dans ce cas mises au service d'un propos gastronomique plutôt qu'astronomique, et servaient à démontrer la singularité d'un projet humain de transformation alimentaire plutôt que la nature générale du vivant. Les recherches de Wolfe-Simon autour de l'arsenic visent à mettre l'unicité microbienne au service d'un propos sur l'universalité biologique, dans le cadre d'un écosystème propice à la survie d'un type particulier de microbe. Pour reprendre les termes d'Ankeny et Leonelli (2011), on destine ce microbe à devenir un organisme modèle dont la «portée représentationnelle» va permettre d'expliquer toutes sortes d'hypothèses concernant la constitution moléculaire du vivant.

Au cours de l'été 2012, les propos de Wolfe-Simon font l'objet de vives critiques. Des chercheurs qui tentent de reproduire ses résultats en sont incapables (Erb et al. 2012, Reaves et al. 2012). Tobias Erb et ses collaborateurs tentent de cultiver la bactérie GFAJ-1 dans un milieu privé de phosphore et enrichi en arsenic mais démontrent, en utilisant un spectromètre de masse, que les composés d'arsenic qui apparaissent dans leurs prélèvements n'ont pas été produits biotiquement par GFAJ-1 mais qu'ils étaient présents dans le milieu de croissance de la bactérie. Cet échec suggère que le laboratoire de Wolfe-Simon a laissé le sentiment prendre le dessus sur la rigueur scientifique, en favorisant la signification qu'ils souhaitaient voir apparaître au détriment de la matérialité du phénomène qu'ils avaient sous les yeux. Croyant avoir affaire à une occurrence unique (GFAJ-1) capable d'éclairer et de définir un terrain universel (le vivant), ils se sont trouvés face à un mirage. Cette défaite ne peut être pour autant considérée comme une victoire de la matérialité. On pourrait plutôt dire que c'est le caractère prescriptif de GFAJ-1, associé à son statut d'organisme modèle, qui a été mis en échec. Ce caractère s'est effondré jusqu'à ce que ce microbe ne soit plus représentatif de rien d'autre que de lui-même: un microbe somme toute ordinaire, voire même, d'après un nombre croissant de chercheurs, 
une erreur scientifique. Pour reprendre un terme utilisé par Nicole Nelson (2013) dans son article sur la manière dont les modèles utilisant des souris en biologie humaine sont construits et déconstruits au gré de la pratique expérimentale et de la rhétorique, l'«échafaudage épistémologique » que constituait GFAJ-1 s'est écroulé sous le poids des déclarations de Wolfe-Simon sur son caractère représentatif. Ce microbe n'est désormais lisible que dans le cadre d'une écologie très particulière, impossible à généraliser au-delà d'elle-même et qui, de surcroît, n’a peut-être même jamais ressemblé à la description qu'en a faite Wolfe-Simon.

\section{La vie de laboratoire du vivant: créer des écosystèmes modèles à partir de simulations de paysages microbiens extraterrestres}

Bien qu'il soit désormais communément admis que Wolfe-Simon a radicalement surestimé l'impact de ses résultats, le projet consistant à penser le «vivant» dans des conditions de possibilité planétaires au sens large reste la marque de fabrique de l'astrobiologie. Ce champ de recherche continue de s'appuyer sur la promesse que les microbes seraient des entités révélatrices, dont les singularités inattendues permettraient de faire apparaître des traits universels du vivant. Les microbes pourraient être qualifiés de «bio-objets», c'est-à-dire selon la définition de Niki Vermeulen et al. (2012), de formes techniques qui acquièrent de l'importance en biologie lorsqu'elles sont pensées dans un rapport métonymique au vivant. Par exemple, des cellules fotales avortées peuvent alternativement être considérées comme des « déchets organiques morts», qui ne sont donc pas des bio-objets, ou bien «être revitalisées en servant de source à des lignées de cellules-souches», devenant alors des bio-objets (Vermeulen et al. 2012: 2) ${ }^{18}$. Les «bio-objets » microbiens sont presque toujours pensés en rapport à un environnement, c'est-à-dire selon le langage de l'écosystème modèle.

Quelque temps après la réfutation des thèses de Wolfe-Simon dans Science en juillet 2012, nous avons rencontré Tanja Bosak, géobiologiste au Massachusetts Institute of Technology (MIT), qui était parmi les premiers scientifiques à exprimer son scepticisme devant les thèses de Wolfe-Simon sur l'arsenic. Son laboratoire est affilié à la NAI, un consortium d'environ quatorze équipes de recherche rattachées à différents laboratoires de recherche, universités et centres de la NASA. Bosak appartient à l'équipe « Naissance de la vie complexe» («Advent of Complex Life»). Spécialiste en Sciences de la Terre, elle s'intéresse à la manière dont notre planète a acquis les propriétés géologiques et biochimiques qui sont aujourd'hui les siennes. Elle cherche par exemple à déterminer quand et comment l'atmosphère de la Terre s'est remplie d'oxygène. On considère généralement que l'oxygénation s'est produite il y a environ un demi-milliard d'années. Comme la cynobactérie qui est à l'origine de cette oxygénation est apparue il y a 2,5 milliards d'années, il reste à comprendre pourquoi ce phénomène a mis si longtemps à se produire. Cependant, il est difficile de comprendre l'histoire microbienne de l'atmosphère oxygénée de la Terre, car les microbes ne se fossilisent pas: ils se contentent de laisser des vides en forme de bulles dans les 


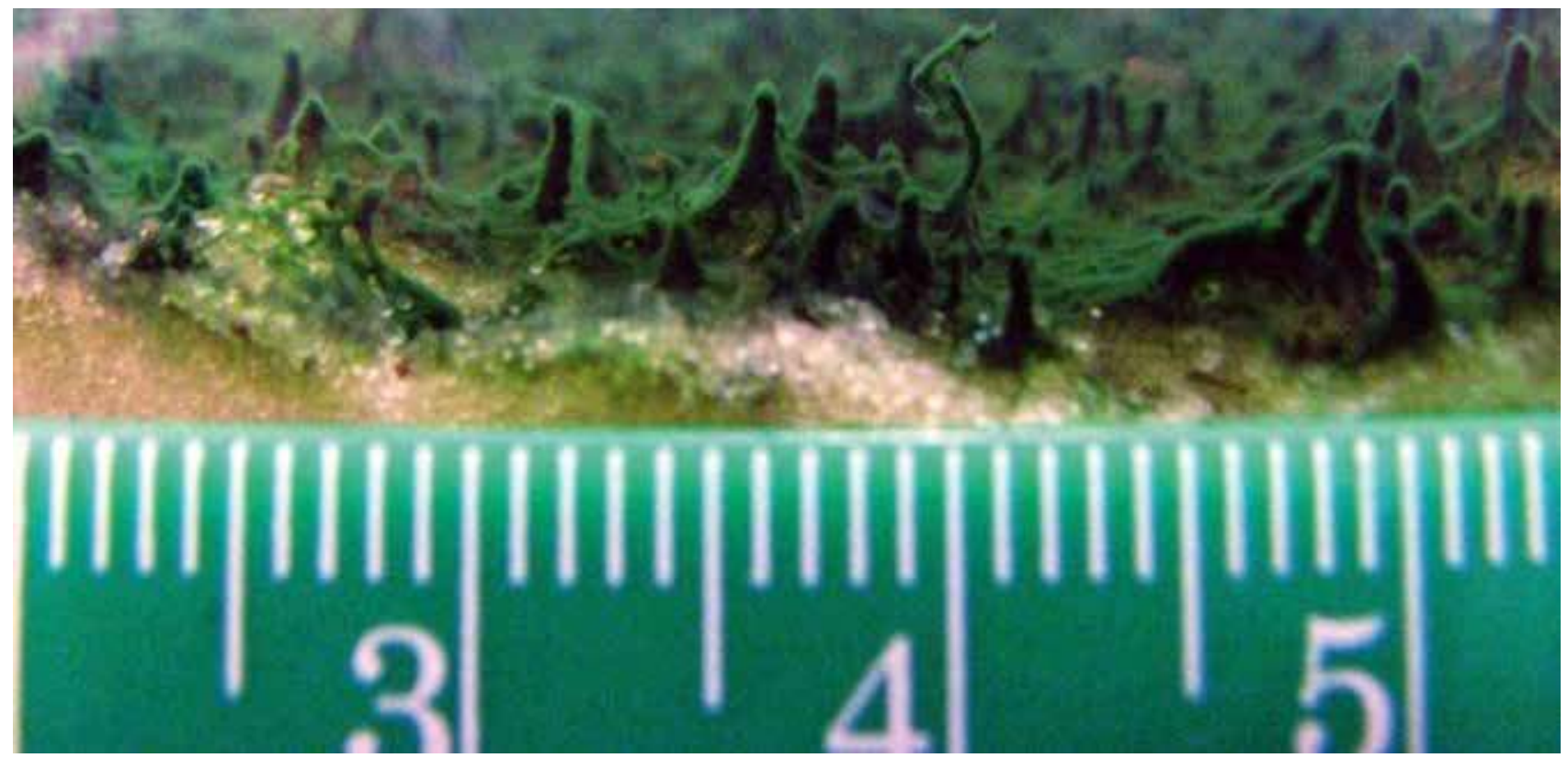

roches, qui constituent les traces de leur activité métabolique passée. La plus grande partie du travail de Bosak consiste à tenter de créer en laboratoire des écosystèmes capables de produire ce type de traces. La chercheuse explique, comme l'avait fait Dutton, que son travail est le même que celui d'un microbiologiste expérimental: elle cultive des collections de microbes dans le but de «traduire leurs comportements et leurs métabolismes en formes», en contours susceptibles de coïncider avec les marques anciennes de plusieurs milliards d'années qui ont laissé leur empreinte dans l'histoire paléontologique de la Terre. Ces contours pourraient constituer des «biosignatures», que la recherche en astrobiologie définit comme «toute propriété mesurable d'un objet planétaire, de son atmosphère, de ses océans, de ses formations géologiques ou de ses prélèvements qui indique que l'eau y est ou y a été présente ». Pour être plus concis, on pourrait parler d'une «empreinte digitale du vivant» (McKay et al. 2002: 625).

Bosak nous a montré certains des travaux sur lesquels s'appuie sa recherche de biosignatures, et nous a conduits jusqu'à un réfrigérateur dans son laboratoire qui contient des dizaines de cultures microbiennes contenues dans de grandes boîtes de Petri. Elle nous a montré différents paysages microbiens cyanobactériens, dont certains ressemblaient à de minuscules jardins sous-marins parsemés de formes coniques: ces derniers pourraient être des écosystèmes modèles qui permettraient d'expliquer comment des cyanobactéries vivant à une époque reculée ont laissé des empreintes coniques dans des roches très anciennes. Ces simulations d'écologies d'apparence extraterrestre peuvent être vues comme des modélisations d'un terroir a-humain, remontant à l'époque où la Terre était jeune et encore dépourvue d'oxygène. 
Tandis que les travaux de Bosak se concentrent sur l'évolution du système Terre, son affiliation à l'équipe «Advent of Complex Life» du MIT/NASA reflète la pertinence plus générale de son travail pour la biologie dans les deux sens du terme (à la fois objet d'étude et discipline). Dans ces recherches, la vie microbienne est précieuse car elle permet d'étayer des intuitions qui pourraient permettre de détecter des signes de vie en général. C'est elle qui permet de relever des biosignatures, que ce soit par le biais des empreintes fossilisées laissées par des formations microbiennes ou par la mesure de concentrations de soufre reflétant une activité métabolique microbienne (comparer avec Helmreich 2006). « Nous ne trouverons jamais d'ADN» provenant des premiers organismes présents sur Terre, nous explique Bosak, «mais nous pouvons retracer ce que faisaient ces organismes ». On notera le rôle complexe que joue la «matérialité » dans ce projet. En effet, une biosignature n'est pas la concrétisation d'une matérialité entièrement présente et caractérisée, mais plutôt un signe vers un monde chimique ou biochimique possible: une "présence absente», pour reprendre le concept de Jacques Derrida (1982 [1972]) qui suggère que l'utilisation d'une signature comme trace d'une présence authentique suppose paradoxalement l'absence de l'agent qui a produit cette signature.

Bosak reste prudente sur la possibilité d'extrapoler à partir de ces modèles microbiens pour tracer des généralisations applicables à d'autres histoires planétaires, et préfère au contraire restreindre les données de son système modèle aux preuves existant dans l'histoire géologique de la Terre. Toutefois, d'autres chercheurs en astrobiologie sont plus prompts à émettre des spéculations d'ordre extraterrestre, et considèrent des absences suggestives (fonds) comme les indicateurs d'éventuelles présences (figures). La revue Astrobiology est pleine d'articles qui postulent des analogies possibles entre les environnements terriens et extraterrestres, et ces démonstrations convoquent presque toujours la vie microbienne (voir Popa et al. 2012). Pour prendre quelques exemples: dans «Life at the wedge: The activity and diversity of Arctic ice wedge microbial communities», les microbiologistes Roland C. Wilhelm et al. écrivent que «la détection récurrente de micro-organismes dans des environnements de glace souterraine comme les coins de glace que l'on rencontre sous les polygones de toundra» suggère que «les sols polygonaux sur Mars [...] pourraient être, ou avoir été, un habitat propice au développement de formes de vie persistantes» (Wilhelm et al. 2012: 347). Et dans «Biosignature detection at an Arctic analog to Europa», Damhnait Gleeson et al. commentent la recherche d'« indications potentielles de la présence de la vie» dans les océans de la lune de Jupiter, Europa, à partir de la « caractérisation d'une série de biosignatures formées par des dépôts de soufre potentiellement analogues [à Europa] relevés sur la surface du glacier arctique de Borup Fiord Pass » (Gleeson et al. 2012: 135). Les microbes arctiques terriens sont considérés comme potentiellement comparables à ceux que l'on trouverait sur Europa (ce n'est pas un hasard si le mot «potentiel» (potential) apparaît dans 635 des 770 articles publiés par Astrobiology).

Ce débat continu sur les implications que présente la recherche sur les microbes terriens pour les mondes extraterrestres provient en partie, comme le suggère Bosak, du fait que de nombreux chercheurs orientent leurs questions de recherche et leurs priorités pour coïncider avec les priorités des missions spatiales de la NASA, qui s'intéressent à la biologie terrestre 
comme un cas particulier susceptible d'être élargi à une échelle plus vaste, et potentiellement universelle. Ainsi, le rover martien Curiosity, qui a atterri sur Mars le 6 août 2012, s'est posé dans un «cratère autrefois recouvert d'eau et [...] contenant des minéraux qui ne peuvent se former que dans l'eau, ainsi que des argiles qui nécessitent un environnement $\mathrm{H}_{2} \mathrm{O}$ ». Le rover contient un laboratoire mobile «conçu pour rechercher les briques de carbone qui pourraient former la base de la vie sur Mars, et explorer les habitats potentiels où la vie pourrait avoir existé ${ }^{19}$ ». Les propriétés de la «vie» que recherche la NASA sont les mêmes qui caractérisent la vitalité microbienne.

Latour et Woolgar dans La vie de laboratoire (1986 [1979]) concluent que le travail des scientifiques consiste à générer des inscriptions et à enregistrer des données qui, si elles sont appuyées par une sociologie suffisamment robuste, deviendront des faits. Dans les travaux de microbiologie évoqués ici, les «signatures» microbiennes fonctionnent comme des inscriptions d'un genre particulier: des inscriptions qui intègrent un certain nombre de conceptions et de modèles du vivant, et d'idées sur la capacité qu'a le vivant de laisser des traces. Une inscription de ce type se veut une description mais elle est aussi, au moins en partie, une prescription: une indication de ce que l'on devrait trouver. Une signature devient une sorte de «bio-objet», un indice formel de vitalité. La vie de laboratoire du «vivant» dépend en grande partie de la manière dont ces inscriptions - comme les vides en forme de bulles dans les roches que Bosak cherche à étudier au moyen d'écosystèmes modèles - sont interprétées, comme autant de descriptions de la manière dont nous nous représentons, de manière prescriptive, le vivant.

\section{Le microbe, un modèle plein de promesses}

Dans la production artisanale de fromage comme en astrobiologie, les praticiens de l'écologie microbienne (dans le cas du fromage, il s'agit à la fois de scientifiques et de non-scientifiques) font appel aux microbes pour donner un ancrage à leurs projets culturels, que ceux-ci visent à valoriser et à stabiliser la production locale et artisanale d'aliments, ou à étendre la portée des spéculations de la biologie sur la vie au-delà de la Terre. De toute évidence, ce recours à la vie microbienne considérée comme une promesse plutôt que comme un péril participe à une vision environnementaliste plus vaste ${ }^{20}$. Nous ne sommes plus dans le monde moderniste de la guerre froide où les ennemis sont présents partout, jusque dans le royaume microbien: tel était l'ethos qui a présidé à la fois à la suprématie du fromage pasteurisé américain après 1949, et à la fondation en 1960 de l'exobiologie pour défendre la Terre contre les microbes venus de l'espace. Les microbes sont aujourd'hui devenus des modèles pour appréhender la nature biotique, à la fois parce qu'ils agissent comme des représentants des dynamiques qui traversent le monde organique dans son ensemble, et parce qu'il sont un indice et une promesse qui permet de réimaginer la nature telle qu'elle est ou pourrait être. On notera cependant que c'est précisément le succès du projet pasteurien qui a rendu possible cette vision optimiste des microbes. 
Les microbes ne peuvent être considérés comme prometteurs que si l'on n'a plus à se préoccuper de la petite vérole, de la polio, du choléra et autre agents de maladies infectieuses.

Nous approfondirons en conclusion le concept d'écosystème modèle, en soulignant encore une fois que ces modèles ne sont pas seulement descriptifs, mais aussi dans le même temps prescriptifs. Cela n’a rien d'une nouveauté: depuis leurs débuts, les modèles écologiques sont lourdement chargés de prescriptions morales, d'autant plus que beaucoup de ces modèles, surtout au xxe siècle, étaient conçus à des fins de contrôle (voir Anker 2002, Toogood 2008). Comme l'observent Lorraine Daston et Fernando Vidal (2003) dans The Moral Authority of Nature, les animaux non-humains (comme l'abeille ou le castor industrieux) ont souvent été tenus pour des modèles de vertu humaine. Le cadre nord-américain auquel appartiennent nos cas a également son importance. Les appels moralisateurs à la nature ont une riche histoire aux États-Unis, un pays que l'historien Perry Miller (1967) a appelé « la nation de la nature». Comme l'ont montré les historiens de l'environnement, ce récit national a influencé des phénomènes qui vont de la fondation des parcs nationaux à l'activisme écologiste (Bak \& Hölbling 2003). Tandis que la science microbienne propose évidemment des grilles de lecture transnationales, la situation du fromage artisanal américain et des recherches de la NASA dans la période post-pastorale et post-guerre froide inscrivent l'histoire microbienne que nous avons racontée ici dans une histoire idéologique et institutionnelle de l'Amérique: une histoire qui pourrait être approfondie en évoquant la manière dont les écosystèmes microbiens sont confrontés aux régimes réglementaires touchant aux produits alimentaires, aux projets de santé publique, aux cadres nationaux de financement, et aux anxiétés qui entourent les biologies nationales (on notera par exemple que la nature microbienne n'a-jusqu'à présent- jamais été intégrée aux discours biopolitiques douteux associés à une certaine pensée américaine de la race). Une telle histoire ferait apparaître la valeur qui a été accordée aux microbes, la manière dont ils ont été abordés et l'identité de ceux qui les ont étudiés ${ }^{21}$.

Comment penser l'intervention humaine dans des écosystèmes modèles? Il est selon nous instructif de penser cet agent par le biais du langage de la «signature », que l'on retrouve dans le monde du fromage artisanal comme dans les discours de l'astrobiologie.

Pour certains fromagers américains, derrière le rêve d'un terroir microbien réside l'espoir qu'en l'absence de pratiques culturelles traditionnelles mises en valeur depuis des générations (comme c'est le cas en Europe et au Royaume-Uni), la diversité microbienne unique qui semble résulter de nouvelles configurations de lieux et de pratiques pourrait apporter une légitimité à des méthodes agricoles et agroalimentaires non traditionnelles. Comme l'expliquait Ivan Larcher lors de son intervention au séminaire sur le fromage dans le Wisconsin, «le rêve de tout fromager est de développer son propre spectre de bactéries, pour développer une signature personnelle. Ce spectre est directement lié à l'endroit où l'on vit, et c'est cela que désigne le concept de terroir ». Ici la signature tracée par les microbes apparaît au point de rencontre entre travail, environnement et territoire. En entrant en interaction avec la pratique humaine, le monde microbien universel peut donner naissance à quelque chose d'unique. Les producteurs comparent par ailleurs leurs pratiques de travail à différentes forces génératrices existant dans 
la nature comme la décomposition. Cette analogie a pour effet de naturaliser des méthodes de production artisanales et de leur conférer, en tant que procédés «naturels», non seulement une légitimité mais aussi un caractère moral dans le sens normalisateur du terme: «Voici la manière dont les aliments devraient être fabriqués. » Si la notion de terroir microbien présente un tel attrait, c'est peut-être parce que les micro-organismes invisibles à l'œil nu semblent, en comparaison avec la race ou l'alimentation des bêtes laitières, l'élément le plus sauvage, et donc le plus autochtone, dans l'écologie de la production du fromage. Cependant, si certaines communautés particulières de microbes apparaissent pour former la croûte d'un fromage, leur présence est en grande partie due aux efforts de l'humain pour cultiver ces microbes - et c'est pour cette raison que la «signature», traditionnellement définie comme la marque unique laissée par la main de l'artisan, est une image qui se prête particulièrement bien aux fromagers. Dans la constitution de la matérialité particulière du fromage, nature et culture sont intimement imbriquées: aucune des deux ne peut être considérée comme précédant l'autre.

Pour les astrobiologistes, le rêve de trouver du vivant ailleurs dans l'univers se nourrit de l'espoir qu'en découvrant une diversité microbienne unique, on pourra modéliser de nouvelles

\section{Une peinture murale de Tara Goreau, sur la grange de Jasper Hill} Farm

Elle représente une lune de fromage bleu Bayley Hazen s'élevant sur les collines, tandis que la Terre et un vaisseau spatial (sous la forme des caves de Jasper Hill) planent au loin - suggérant que nous ne serions pas sur la Terre ici au Vermont, écrit Tara Goreau (Sutkoski, 2012).

Notez également la ressemblance de la Lune, piquée de vaches bleues, avec une boîte de Pétri, une culture microbienne.

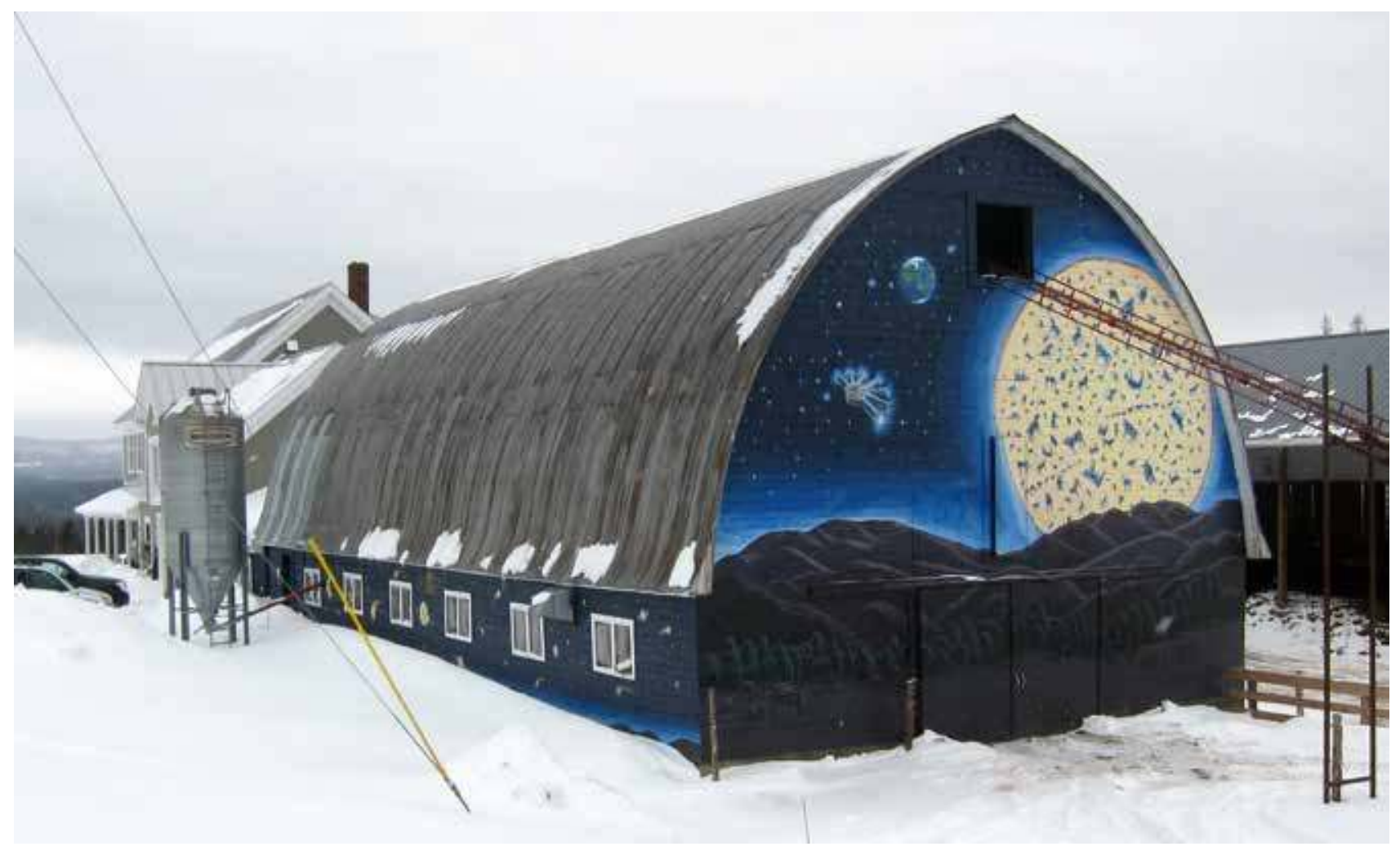


manières d'exister en tant qu'organisme (autrement dit, d'autres manières d'être vivant) qui pourraient permettre d'élargir à l'échelle de l'univers ce que l'on considère comme le vivant. Pour citer la feuille de route sur l'astrobiologie de la NASA: «Il faut développer des catalogues de biosignatures qui reflètent les caractéristiques fondamentales et universelles du vivant, sans s'arrêter aux seuls attributs qui constituent des solutions locales au problème de la survie. » (Des Marais et al. 2003). Dans ce cas, la signature découle de la découverte de l'ubiquité dans le particulier: la recherche de preuves de la diversité microbienne permet d'accéder à l'universel.

Comme on le sait, une signature est souvent apposée pour garantir une promesse. Or, comme le suggère Michael Fortun (2008), une promesse a tendance à produire une image de l'avenir qui, par son énonciation même, a cet effet mystérieux d'infléchir et de (ré)orienter le présent. Les signatures reposent aussi sur une économie morale commune du sens. Et de fait, l'une des caractéristiques principales des organismes modèles - sur laquelle nous nous appuyons quand nous affirmons que les microbes sont des modèles aussi bien dans le sens prescriptif que dans le sens descriptif du terme - est que ceux-ci sont souvent communs à différents laboratoires et centres de recherche ${ }^{21}$. Les types de microbes contenus dans le fromage, ou plutôt les activités microbiennes qui constituent ce dernier, coïncident avec les catégories communes de forme et de saveur (par exemple les fromages à croûte lavée, à croûte fleurie ou à pâte persillée). Les recherches en microbiologie de Marcellino ou de Dutton et de Wolfe suggèrent en effet que la recette (et donc la technique) est l'indicateur le plus fiable pour savoir « qui » sera présent dans la croûte d'un fromage donné - ce qui explique pourquoi Microbacterium gubbeenese a été retrouvé sur des fromages français du même type. Parallèlement, en astrobiologie, les microbes sont considérés comme des indicateurs des caractéristiques communes à tous les êtres vivants. Le règne microbien, commun à différentes échelles et à différents contextes, alternativement et simultanément universel, omniprésent et unique, est devenu une nouvelle ressource pour ceux qui cherchent à identifier de nouveaux modèles de vie avec la nature biologique ou au sein de cette dernière. La question n'est plus seulement: «Qu'est-ce que le vivant?», mais plutôt «À quelles formes de vivant souhaitons-nous nous intéresser?»

Cette question est applicable non seulement au travail des fromagers et des astrobiologistes, mais aussi curieusement à certains des nouveaux matérialistes dons nous avons entrepris de faire un examen critique. En effet, la phénoménologie putativement a-humaine, non-humaine, in-humaine et extraterrestre que mettent en avant ces discours s'accompagne souvent de visées morales sous-jacentes. Bennett (2010) est explicite à cet égard lorsqu'elle écrit: «J'ai l'intuition que l'image d'une matière morte ou totalement instrumentalisée alimente l'hybris humaine et nos fantasmes de conquête et de consommation qui détruisent la planète.» (Ibid. : ix). Bennett écrivait quelques années plus tôt dans une profession de foi que le «matérialisme vitaliste souligne la proximité et l'intimité entre humains et non-humains. Et c'est sur ce point, dans la conscience accrue de cette interaction, que le matérialisme vitaliste peut contribuer à un éthos écologique» (Bennett 2004: 365). Tout comme les amateurs de fromage et les astrobiologistes, Bennett cherche à concevoir un modèle satisfaisant de système écologique. Vibrant Matter prolonge et adapte une tradition qui remonte aux thèses du xixe siècle selon lesquelles la 

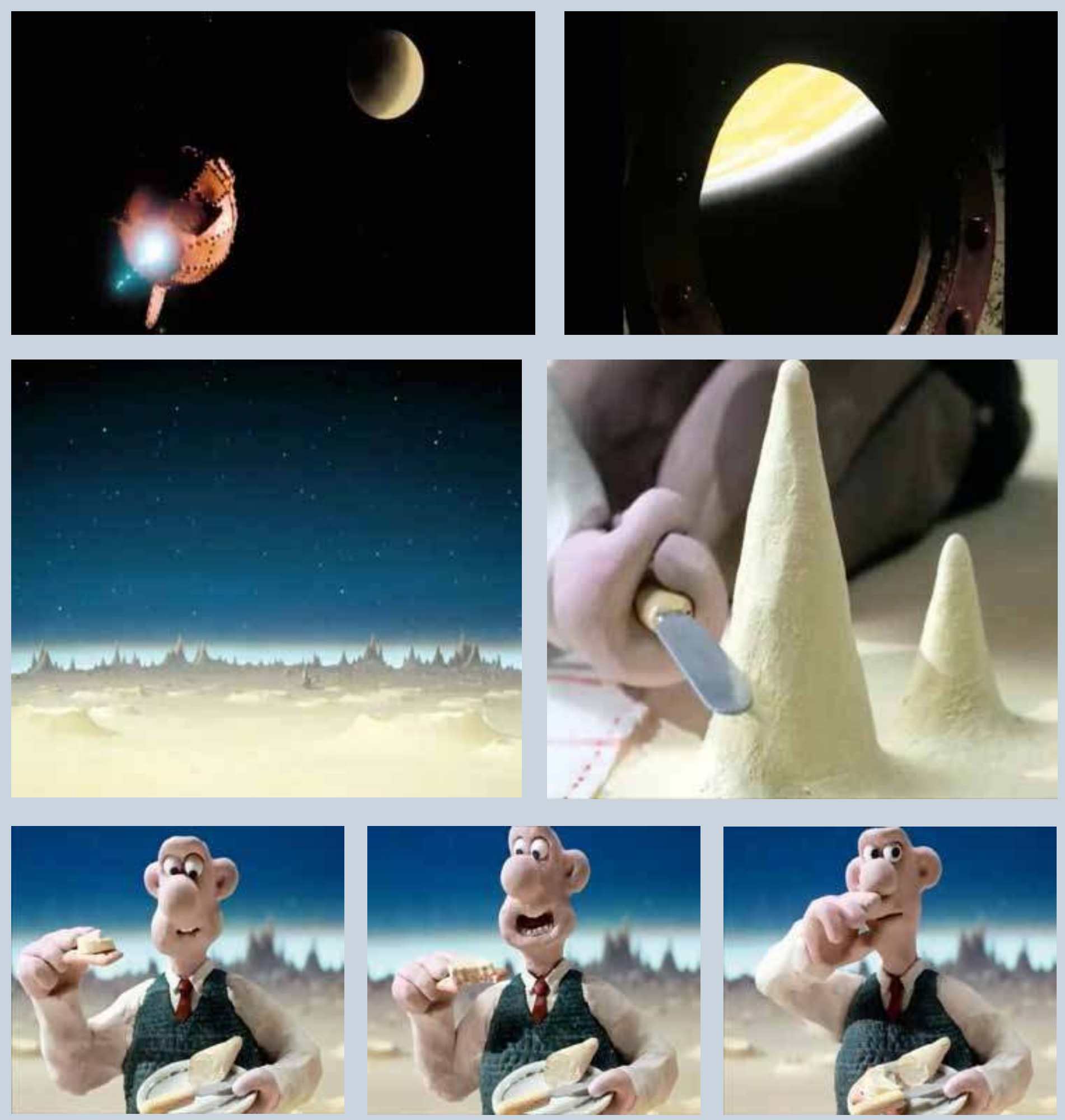
matière «animée» pourrait garantir une vision démocratique du monde. Dans leur biographie de Charles Darwin, les historiens de la biologie Desmond et Moore (1991 : 223) affirment que l'idée d'une matière « animée» faite d'« atomes vivants » telle que la postulent des figures comme le botaniste Robert Brown, un contemporain de Darwin, «apporte un fondement scientifique à [...] la croyance dans la faculté de l'homme libre de contrôler sa propre destinée. [...] Elle fournit une analogie politique idéale: le pouvoir de la base, le "mandat" accordé aux représentants, émanant des "atomes sociaux", c'est-à-dire du peuple ${ }^{22}$. Si le nouveau matérialisme a laissé de côté les aspects explicitement «sociaux», qui ont été remplacés par l'« écologie», cette conception est elle aussi imprégnée du désir de nouveaux écosystèmes modèles - ou bien, pour changer de registre, d'écologies modèles, où le terme d'écologie désigne également la description théorique de rapports organiques. Les écologies modèles sont des outils contemporains que les scientifiques et leurs interlocuteurs (dont nous, les auteurs, faisons partie) utilisent pour décrire les formes que prend leur désir de modalités exemplaires pour penser l'imbrication entre l'humain et une agentivité non-humaine.

Examinons pour conclure l'image peinte sur le côté de la grange de la ferme de Jasper Hill, qui représente une lune en fromage. Cette image n'est pas sans rappeler Une grande excursion (A Grand Day Out), un court-métrage animé de science-fiction dans lequel deux personnages en pâte à modeler embarquent pour la Lune à bord d'une fusée spatiale bricolée, dans l'espoir d'y trouver du fromage pour leur pique-nique. En arrivant sur la surface de la Lune, Wallace, inventeur excentrique et grand amateur de fromage, et Gromit, son fidèle compagnon canin plein de ressources, partent en quête de fromage. Wallace effectue des prélèvements à l'aide d'un couteau à fromage et explique à Gromit: «Cela ne ressemble à aucun fromage que j’aie jamais goûté. » La plaisanterie tient bien sûr au fait que Wallace prend au pied de la lettre la vieille croyance européenne selon laquelle, comme le répète Wallace pendant le film, «la lune est faite de fromage». Wallace est par certains aspects assez semblable aux producteurs de fromage et aux astrobiologistes que nous avons rencontrés, dans leur quête de nouvelles possibilités gastronomiques et astronomiques. Cependant, il pourrait aussi être comparé à certains des nouveaux matérialistes qui, tout à leur désir d'intégrer les dernières découvertes de la physique, courent le risque de prendre pour vérité littérale des thèses qui existent dans un certain cadre historique et culturel. Il est toutefois intéressant de noter que la première occurrence de l'idée que «la lune est faite de fromage vert», que l'on relève en 1546 dans une fable de John Heywood, apporte un éclairage épistémologique légèrement différent : en effet, dans cette fable, un renard rusé persuade un loup crédule que le reflet de la lune dans l'eau est un fromage rond. En lisant cette fable comme une allégorie de notre sujet, on pourrait dire que la science ne produit pas de simples reflets du monde, ni des visions déformées de ce dernier, mais plutôt des interprétations ou des modèles, qui sont parfois imprégnés par nos désirs - notamment ceux que suscitent les fromages célestes ou l'existence de compagnons cosmiques. 


\section{Notes}

1. National Institutes of Health, Human Microbiome Project Program Highlights, 2013. [En ligne] : commonfund.nih.gov/HMP/programhighlights.aspx.

2. Sur la «microbiopolitique», voir Paxson 2008.

3. Cette approche est étroitement liée à l'intérêt des STS pour les cellules et la cellularité. Voir par exemple les travaux sur les cellules-souches (Thompson 2013) ou bien ceux qui réimaginent la biologie humaine à travers le prisme de la biologie cellulaire humaine (Landecker 2007).

4. En février 2013, la US Food and Drug Administration et Health Canada ont publié un rapport quantitatif provisionnel qui évalue en termes de santé publique le risque de listériose que présente la consommation de fromages à pâte molle (fromages de type brie ou camembert). Bien que le rapport lui-même n'émette aucune recommandation en termes de politiques publiques, la direction de l'American Cheese Society a exprimé ses craintes quant au fait que ce rapport ouvre la voie pour les autorités sanitaires à de futures restrictions réglementaires sur la vente aux États-Unis de fromages au lait cru, restrictions que le secteur du fromage artisanal considère injustifiées (voir Paxson 2013).

5. On peut observer un recadrage du même ordre de la vie microbienne dans le champ de la conservation des objets d'art. Tandis que les microbes ont longtemps été considérés comme les ennemis des objets d'art, la spécialiste en biologie de l'évolution Nicoletta Barbabietola et al. écrivent dans une revue sur la conservation du patrimoine que les microbes «peuvent être responsables de la destruction d'objets du patrimoine culturel, mais [que] cette action "destructrice" peut être utilisée pour la suppression biologique de patines de surface détériorées, voire même convertie en une action "constructive" » (Barbabietola et al. 2012: 71). Nous tenons à remercier Grace Kim qui dans son article «Cultures on culture: Recruiting bacteria in the conversation of art» (2013) a attiré notre attention sur le tournant microbien qui s'est opéré dans la conservation des objets d'arts. Kim rapporte l'usage par les conservateurs de termes comme «écologique» («eco-friendly») et « respectueux» («respectful») pour évoquer les microbes mobilisés pour la préservation et le nettoyage des objets.
6. À propos d'«artificialité », on notera que le mot même de «microbe» (qui signifie à peu de chose près «petite vie») implique un artifice, du fait du caractère culturellement construit des techniques de mesure et d'observation nécessaires pour rendre les microbes observables.

7. Pour une analyse bibliométrique, voir Van Heur et al. 2013.

8. Pour une critique de cette approche, voir Hemmings 2005, Martin 2013.

9. Sur la «chorégraphie ontologique» associée aux pratiques de reproduction assistée, voir Thompson 2005.

10. On comparera cette approche avec celle de Law \& Lien 2013.

11. Voir aussi Daniel Miller (2005), dont la conception de la matérialité participe d'un dialogue plus profond avec les études de culture matérielle, et offre à notre sens un point de départ plus utile.

12. Les lecteurs s'intéressant à l'histoire de la sociologie des sciences se souviendront du débat qui a opposé Harry Collins et Steven Yearly (1992) à Michel Callon et Bruno Latour (1992). Collins et Yearly reprochaient à Callon et Latour, en plaçant l'accent sur les actants, d'introduire subrepticement un réalisme et un matérialisme dépourvus de réflexivité. Il est vrai que lorsque Callon (1986) parle de la «complicité » des coquilles Saint-Jacques, en faisant référence à leur tendance à s'accrocher aux engins scientifiques de pêche dans les eaux de la baie de St Brieuc, il prête à ces mollusques une forme d'agentivité qui relève bien du réalisme - voire même du darwinisme, pour être plus précis, puisque c'est avant tout de reproduction qu'il s'agit (Callon 1986). Cependant la théorie de l'acteur-réseau développée par Callon et Latour, que ce soit dans son ensemble ou dans ses développements ultérieurs, présente souvent l'avantage de retracer la manière dont la «matérialité » en tant que telle -ou les «matérialités »- émerge à partir de pratiques de connexion et d'association, et ne précède pas ces dernières.

13. Communication personnelle, 2013.

14. Communication personnelle.

15. Enquête nationale menée en ligne en 2009 auprès de 177 producteurs de fromage par Heather Paxson et Elizabeth Page. 
16. «Raw Milk and You »; ce blog n'existe plus en 2017 (NdlR).

17. planetaryprotection.nasa.gov/missions-planned/.

18. À comparer avec la notion de «l'interface FIV-cellules souches » dans Franklin 2006.

19. www.space.com/16902-mars-rover-curiosity-lifebuilding-blocks.html. L'article de Janet Vertesi (2012) «Voir comme un Rover» élargit le point de vue à celui du biochimiste.

20. L'environnementalisme actuel relève à la fois de l'échelle micro et macro. Micro: le microbiome humain et ce que nous pourrions appeler le microbiome fromager peuvent être mis en juxtaposition à un niveau infracorporel. La nutritionniste Johanna Lampe suggère: «L'influence des microbes vivants contenus dans les produits laitiers fermentés et dans certains fromages sur le microbiome intestinal et les fonctions immunitaires humaines est un domaine d'étude en pleine expansion.» (2011 : 464S). On peut voir cette étude microbienne de la nutrition et de la santé humaines comme une sorte d'environnementalisme au service du développement personnel. Macro: l'astrobiologie réimagine l'univers comme écosystème. Le cosmos n'est plus un «espace lointain » mais un «environnement» plus ou moins extrême (Olson, 2010) et/ou habitable (Messeri 2011). L'abondance même des microbes permet à ces différentes thèses d'être défendues sur des échelles radicalement différentes.

21. Une comparaison transnationale pourrait par ailleurs aider à comprendre en quoi cette histoire est spécifiquement américaine. On pourrait prendre comme point de comparaison, dans le Japon de la fin du xxe siècle, le «Mont Microbe» de Kyoto, un temple à la mémoire des nombreux microbes morts pour la science. Comme le rapporte le microbiologiste Takeo Kasabo lorsqu'il évoque la fondation du site en 1981 : «Grâce aux remarquables progrès de la bactériologie au cours des dernières années, on a développé toutes sortes de nouvelles enzymes qui ont joué un rôle significatif dans de nombreux domaines. Mais quel égoïsme de la part des humains d'avoir été trop indifférents au massacre de ces milliards de vies minuscules, dans l'ombre des glorieux progrès technologiques, pour prêter attention à ce sacrifice! Déplorant profondément ce fait, j'ai créé le Mont Microbe (Microbe Mont) dans l'enceinte sacrée du saint Temple Manshuin, au pied du versant ouest du mont Hiei. » Kasabo rapporte une ode qui est calligraphiée sur le site:

"Aux innombrables âmes des Microbes

Qui se sont dévouées et sacrifiées

Pour l'existence des Humains,

Nous présentons notre plus profond respect.

Nous tenons ici un Service Mémorial

Pour le repos et la consolation de leurs âmes, En bâtissant un Mont des Microbes.

Archevêque Endoh, 40e moine de la Succession du Temple Manshuin, Calligraphie de l'Ode au Microbe de Kinichiro Sakaguchi. » [En ligne] kinduka.main. jp/page009.html. Merci à l'historienne Victoria Lee de nous avoir signalé le Mont Microbe.

21. «[L]es organismes modèles [...] reposent sur une série de présupposés communs concernant les objectifs de la recherche, qui consistent généralement à tenter de générer une connaissance complète des processus fondamentaux à l'œuvre dans ces organismes, notamment des processus moléculaires, cellulaires et développementaux; l'organisme modèle est en ce sens considéré comme un tube à essai permettant de parvenir à une pleine compréhension de tous les processus biologiques.» (Ankeny \& Leonelli 2011: 317).

22. Voir aussi James E. Strick, qui suggère que pour les tenants de la « génération spontanée» du xixe siècle, les théories de la matière vivante étaient associées à l'espoir d'une « réforme politique et sociale démocratique» (Strick 2000: 39).

\section{Remerciements}

Nous tenons à remercier les chercheurs et les producteurs de fromage qui ont participé à notre recherche. Heather Paxson remercie Rachel Dutton, Ben Wolfe, Andy Kehler et Mateo Kehler. Stefan Helmreich remercie tout particulièrement Tanja Bosak. Cet article est né d'une présentation commune pour le Salon des technosciences au Jackman Humanities Institute de l'Université de Toronto (Ontario) au Canada. Nous remercions Natasha Myers et Michelle Murphy pour leur invitation. L'exposé a ensuite été développé pour être présenté à l'Institute for Advanced Study de l'Université 
du Minnesota. D’autres versions de cet article ont été présentées dans le cadre du département d'anthropologie du Graduate Center à la City University of New York; du programme «Science, Technology and Society» de l'Université du Michigan; des Klopsteg Lectures du programme «Science in Human Culture» de la Northwestern University; sous la forme de document de travail pour le «Political Ecology Working Group » à l'Université de Harvard; et sous la forme d'une conférence devant le département de sciences humaines et sociales de l'Université de Bergame, Italie. Nous remercions aussi Cristina Grasseni, Grace Kim, Nicole Labruto, Hannah Landecker, Caterina Scaramelli et Karen-Sue Taussig pour leurs retours très utiles sur les versions provisoires de cet article. Enfin, nous remercions les deux évaluateurs anonymes de la revue Social Studies of Science ainsi que son rédacteur en chef Sergio Sismondo pour le travail remarquable qu'il a fourni pour donner à cet article sa forme définitive.

Nous remercions aussi Amah Edoh, Cristina Grasseni, Grace Kim, Nicole Labruto, Hannah Landecker, Caterina Scaramelli et Karen-Sue Taussig pour leurs retours très utiles sur les versions provisoires de cet article.

\section{Financement}

Cet article prolonge des recherches qui ont initialement reçu le soutien, entre autres, de la Wenner-Gren Foundation for Anthropological Research, bourses nº693 (Helmreich) et nº 7641 (Paxson).

\section{Droits de reproduction}

La rédaction remercie tout particulièrement Ayn Cavicchi pour son aide précieuse dans la recherche et l'acquisition des droits et autorisations de reproduction.

\section{Traduction}

Cet article est paru sous le titre original: «The perils and promises of microbial abundance: Novel natures and model ecosystems, from artisanal cheese to alien seas », Social Studies of Science 44(2), 2014 : 165-193. [En ligne] : doi: 10.1177/0306312713505003.

La traduction française a été réalisée par Valentine Leÿs pour TechniquesECulture; qu'elle en soit ici chaleureusement remerciée (NdlR).

\section{Les auteurs}

Heather Paxson, professeur d'anthropologie au Massachusetts Institute of Technology, elle s'intéresse à la façon dont les gens se perçoivent comme des êtres moraux à travers les pratiques quotidiennes, en particulier les activités familiales et alimentaires. Elle est l'auteur de The Life of Cheese: Crafting Food and Value in America (University of California Press, 2013), qui analyse comment l'artisanat est devenu une nouvelle source de valeur culturelle et économique dans les paysages américains de production et de consommation.

Stefan Helmreich est l'auteur Alien Ocean: Anthropological Voyages in Microbial Seas (University of California Press, 2009), une étude des biologistes marins qui travaillent dans des domaines généralement hors de vue et de portée: le monde microscopique, la mer profonde et les océans en dehors des souverainetés nationales. Le livre le plus récent de S. Helmreich, Sounding the Limits of Life: Essays in the Anthropology of Biology and Beyond (Princeton University Press, 2016) interroge les redéfinitions menées par les scientifiques contemporains de concepts cruciaux tels que la vie, l'eau et le son. 


\section{Iconographie}

Image d'ouverture. The parallel microscopic Universe III. CC BY Sofia Vini / https://www.behance.net/gallery/ 27318019/AURUM.

1. C Russell Lee (1903-1986) / Bibliothèque du Congrès

2. (C) Heather Paxson.

3. Proctor Crater. Dune Field (C) Nasa, public domain

\section{Références}

Alaimo, S. 2010 Bodily Natures: Science, Environment and the Material Self. Indianapolis, IN : Indiana University Press.

Ankeny, R.A. \&S. Leonelli 2011 «What's so special about model organisms? », Studies in History and Philosophy of Science Part A 42(2): 313-323.

Anker, P. 2002 Imperial Ecology: Environmental Order in the British Empire, 1895-1945. Cambridge, MA: Harvard University Press.

Bak, H. \& W.W. Hölbling (dir.) 2003 Nature's Nation Revisited: American Concepts of Nature from Wonder to Ecological Crisis. Amsterdam: VU University Press.

Barad, K. 2007 Meeting the Universe Halfway: Quantum Physics and the Entanglement of Matter and Meaning. Durham, NC: Duke University Press.

Barbabietola, N., Tasso, F., Grimaldi, M., Alisi, C., Chiavarini, S., Marconi, P., Perito, B. \& A.R. Sprocati 2012 «Microbe-based technology for a novel approach to conservation and restoration », Energia, Ambiente e Innovazione: 69-76.

Bennett, J. 2004 « The force of things: Steps toward an ecology of matter», Political Theory 32(3): 347-372.

- 2010 Vibrant Matter: A Political Ecology of Things. Durham, NC: Duke University Press.

Butler, J. 2009 [1993] Ces corps qui comptent. De la matérialité et des limites discursives du sexe. Trad. C. Nordmann. Paris: Éditions Amsterdam [Bodies that Matter: On the Discursive Limits of "Sex". New York: Routledge].

Callon, M. 1986 « Some elements of a sociology of translation: Domestication of the scallops and the fishermen of St. Brieuc Bay » in J. Law (dir.) Power, Action E Belief: A New Sociology of Knowledge. Londres: Routledge and Kegan Paul: 196-233.

Callon, M. \& B. Latour 1992 «Don't throw the baby out with the bath school! A reply to Collins and Yearley » in A. Pickering (dir.) Science as Practice and Culture. Chicago, IL: University of Chicago Press: 343-368.
4. C Tanja Bosak, avec son aimable autorisation.

5. (C) Stefan Helmreich.

6. A Grand Day Out. Photogrammes tirés du court métrage d'animation de Nick Park et Peter Lord (Aardman Animations), premier épisode de Wallace \& Gromit, 1989.

Collins, H. \& S. Yearley 1992 «Epistemological chicken» in A. Pickering (dir.) Science as Practice and Culture. Chicago, IL: University of Chicago Press: 301-326.

Coole, D. \& S. Frost (dir.) 2010 New Materialisms: Ontology, Agency, and Politics. Durham, NC: Duke University Press.

Creager, A. 2002 The Life of a Virus: Tobacco Mosaic Virus as an Experimental Model, 1930-1965. Chicago, IL: University of Chicago Press.

Daston, L. \& F. Vidal (dir.) 2003 The Moral Authority of Nature. Chicago, IL: University of Chicago Press.

Demossier, M. 2011 «Beyond terroir: Territorial construction, hegemonic discourses, and French wine culture», Journal of the Royal Anthropological Institute $17: 685-705$

Derrida, J. 1982 [1972] «Signature event context » in Margins of Philosophy (trad. + notes suppl. A. Bass). Chicago, IL: University of Chicago Press : 309-330 [ Signature, événement, contexte» in Marges de la philosophie. Paris: Minuit].

Des Marais, D.J., Allamandola, L.J., Benner, S.A., Boss, A.P., Deamer, D., Farmer, J.D. et al. 2003 « The NASA Astrobiology Roadmap », Astrobiology 3(2): 219-235.

Desmond, A. \& J. Moore 1991 Darwin: The Life of a Tormented Evolutionist. New York: W.W. Norton.

Dunn, E. 2007 «Escherichia coli, corporate discipline and the failure of the sewer state», Space and Polity 11(1): 35-53.

Dutton, R. 2011 «Small world: A rind researcher captures the microscopic residents of cheese», Culture: The Word on Cheese 3(2): 74-81.

- 2012 «Microbial diversity and interactions» The Science of Artisan Cheese, North Cadbury Court, Somerset, UK, 28-29 août.

Erb, T.J., Kiefer, P., Hattendorf, B., Günther, D. \& J.A. Vorholt 2012 «GFAJ-1 is an arsenate-resistant, 
phosphate-dependent organism », Science 337(6093): 467-470.

Farrell, J. 2005 Invisible Allies: Microbes that Shape Our Lives. New York: Farrar Straus Giroux.

Felder, D., Burns, D. \& D. Chang 2012 « Defining microbial terroir: The use of native fungi for the study of traditional fermentative processes", International Journal of Gastronomy and Food Science 1(1): 64-69.

Fortun, M. 2008 Promising Genomics: Iceland, deCODE Genetics, and a World of Speculation. Berkeley, CA: University of California Press.

Franklin, S. 2006 «Embryonic economies: The double reproductive value of stem cells », BioSocieties 1(1): 71-90.

- 2007 Dolly Mixtures: The Remaking of Genealogy. Durham, NC: Duke University Press.

Gleeson, D.F., Pappalardo, R.T., Anderson, M.S., Grasby, S.E., Mielke, R.E., Wright, K.E. et al. 2012 «Biosignature detection at an arctic analog to Europa », Astrobiology 12(2): 135-150.

Haraway, D. 1989 Primate Visions: Gender, Race, and Nature in the World of Modern Science. New York: Routledge.

Helmreich, S. 2003 « Trees and seas of information: Alien kinship and the biopolitics of gene transfer in marine biology and biotechnology ", American Ethnologist 30(3): 340-358.

—. 2006 «The signature of life: Designing the astrobiological imagination», Grey Room 23(4): 66-95.

- 2009 Alien Ocean: Anthropological Voyages in Microbial Seas. Berkeley, CA: University of California Press.

Hemmings, C. 2005 «Invoking affect: Cultural theory and the ontological turn », Cultural Studies 19(5): 548-567.

Hird, M. 2009 The Origins of Sociable Life: Evolution after Science Studies. Basingstoke: Palgrave Macmillan.

Ingold, T. 2007 " Materials against materiality », Archaeological Dialogues 14(1): 1-16.

- 2012 «Toward an ecology of materials», Annual Review of Anthropology 41 : 427-442.

Ingram, M. 2011 «Fermentation, rot, and other human-microbial performances » in M.J. Goldman, P. Nadasdy, M.D. Turner (dir.) Knowing Nature: Conversations at the Intersection of Political Ecology and Science Studies. Chicago, IL: University of Chicago Press: 99-112.

Katz, S.E. 2003 Wild Fermentation: The Flavor, Nutrition, and Craft of Live-Culture Foods. White River Junction, VT: Chelsea Green Publishing.
- 2012 The Art of Fermentation: An In-Depth Exploration of Essential Concepts and Processes from around the World. White River Junction, VT: Chelsea Green Publishing.

Kelty, C.M. 2012 «This is not an article: Model organism newsletters and the question of "open science" ", BioSocieties 7(2): 140-168.

Kim, G. 2013 «Cultures on culture: Recruiting bacteria in the conversation of art », First-year paper, Doctoral Program in History, Anthropology, and Science, Technology \& Society, Massachusetts Institute of Technology, Cambridge, MA, ms.

Kirksey, S.E. \& S. Helmreich 2010 «The emergence of multispecies ethnography », Cultural Anthropology 25(4): 545-575.

Kohler, R.E. 1994 Lords of the Fly. Chicago, IL: University of Chicago Press.

Kurtz, H., Trauger, A. \& C. Passidomo 2013 «The contested terrain of biological citizenship in the seizure of raw milk in Athens, Georgia », Geoforum 48: 136-144.

Lampe, J. 2011 «Dairy products and cancer», Journal of the American College of Nutrition 30(5): 464S-470S.

Landecker, H. 2007 Culturing Life: How Cells Became Technologies. Cambridge, MA: Harvard University Press.

Latour, B. 1987 Science in Action: How to Follow Scientists and Engineers through Society. Cambridge, MA: Harvard University Press.

- 1988 [1984] The Pasteurization of France. Trad. A. Sheridan \& J. Law. Cambridge, MA: Harvard University Press [Les microbes: guerre et paix, suivi de Irréductions. Paris: Métailié.]

Latour, B. \& S. Woolgar 1986 [1979] Laboratory Life: The Construction of Scientific Facts. $2^{e}$ éd. rév. Princeton, NJ : Princeton University Press [Trad. fr. M. Biezunski 1988 La vie de laboratoire. La production des faits scientifiques. Paris: La Découverte].

Law, J. \& M.E. Lien 2013 «Slippery: Field notes in empirical ontology », Social Studies of Science 43(3): 363-378.

McCalman, M. \& D. Gibbons 2009 Mastering Cheese: Lessons for Connoisseurship from a Maître Fromager. New York: Clarkson Potter.

McFall-Ngai, M., Hadfield, M.G., Bosch, T.C.G., Carey, H.V., Domazet-Lošo, T., Douglas, A.E. et al. 2013 «Animals in a bacterial world, a new imperative for the life sciences», PNAS 110(9): 3229-3236. [En ligne] doi: 10.1073/pnas.1218525110. 
McKay, D.S., Clemett, S., Thomas-Keprta, K. \& E.K. Gibson 2002 « Recognizing and interpreting biosignatures, Abstract \#12873 », (communication orale) - The classification of biosignatures. Astrobiology 2(4): 625-626.

McKibben, B. 2006 [1989] The End of Nature. New York: Random House.

McMurry, S. 1995 Transforming Rural Life: Dairying Families and Agricultural Change, 1820-1885. Baltimore, MD: Johns Hopkins University Press.

Marcellino, N., Beuvier, E., Grappin, R., Guéguen, M. \& D.R. Benson 2001 « Diversity of Geotrichum candidum strains isolated from traditional cheesemaking fabrications in France », Applied and Environmental Microbiology 67(10): 4752-4759.

Martin, E. 2013 «The potentiality of ethnography and the limits of affect theory », Current Anthropology 54(Suppl. 7): S149-S158.

Massumi, B. 1996 «The autonomy of affect» in P. Patton (dir.) Deleuze: A Critical Reader. Oxford: Blackwell, pp. 217-239.

Messeri, L. 2011 Placing Outer Space: An EarthBased Ethnography of Extraterrestrial Worlds. PhD Dissertation, Massachusetts Institute of Technology, Cambridge, MA.

Miller, D. (dir.) 2005 Materiality. Durham, NC: Duke University Press.

Miller, P. 1967 Nature's Nation. Cambridge, MA: The Belknap Press/Harvard University Press.

Mol, A. 2002 The Body Multiple: Ontology in Medical Practice. Durham, NC: Duke University Press.

National Institutes of Health 2013 «Human microbiome project program highlights», [en ligne] : commonfund. nih.gov/HMP/programhighlights.aspx.

Nelson, N. 2013 «Modeling mouse, human, and discipline: Epistemic scaffolds in animal behavior genetics », Social Studies of Science 43(1): 3-29.

Nerlich, B. \& I. Hellsten 2009 «Beyond the human genome: Microbes, metaphors and what it means to be human in an interconnected post-genomic world », New Genetics and Society 28(1): 19-36.

Nestle, M. 2003 Safe Food: Bacteria, Biotechnology, and Bioterrorism. Berkeley, CA: University of California Press.

Neuman, W. 2011 «Raw milk cheesemakers fret over possible new rules», New York Times, 4 février, Bl.
Olson, V. 2010 American Extreme: An Ethnography of Astronautical Visions and Ecologies. PhD Dissertation, Rice University, Houston, TX.

O'Malley, M.A. 2011 « Decentering humans? Imagining a microbially inspired sociology», Metascience 20: 127-130.

O’Malley, M.A. \& J. Dupré 2007 «Size doesn't matter: Towards a more inclusive philosophy of biology », Biology and Philosophy 22: 155-191.

Paxson, H. 2008 «Post-Pasteurian cultures: The microbiopolitics of raw-milk cheese in the United States », Cultural Anthropology 23(1): 15-47.

- 2010 «Cheese cultures: Transforming American tastes and traditions», Gastronomica 10(4): 35-47.

- 2013 The Life of Cheese: Crafting Food and Value in America. Berkeley, CA: University of California Press.

Pollan, M. 2013 Cooked: A Natural History of Fermentation. New York: Penguin.

Popa, R., Smith, A.R., Popa, R., Boone, J. \& M. Fisk 2012 «Olivine-respiring bacteria isolated from the rock-ice interface in a lava-tube cave, a Mars analog environment », Astrobiology 12(1): 9-18.

Pottage, A. 2006 « Too much ownership: Bioprospecting in the age of synthetic biology», BioSocieties 1(2): 137-158.

Rabinow, P. 1992 «Artificiality and enlightenment: From sociobiology to biosociality» in J. Crary, S. Kwinter (dir.) Incorporations. New York: Zone: 234-252.

Rader, K. 2004 Making Mice: Standardizing Animals for American Biomedical Research, 1900-1955. Princeton, NJ : Princeton University Press.

Ramsden, E. 2011 « Model organisms and model environments : A rodent laboratory in science, medicine and society», Medical History 55(3): 365-368.

Reaves, M.L., Sinha, S., Rabinowitz, J.D., Kruglyak, L. $\&$ Redfield, R. 2012 «Absence of detectable arsenate in DNA from arsenate-grown GFAJ-1 cells », Science 337(6093): 470-473.

Sagan, D. 2011 «The human is more than human: Interspecies communities and the new "facts of life" », Society for Cultural Anthropology Culture at Large Forum, 110th Annual Meeting of the American Anthropological Association, Montréal, QC, Canada, 16-20 novembre.

Schrader, A. 2010 « Responding to Pfiesteria piscicida (the fish killer): Phantomatic ontologies, indeterminacy, 
and responsibility in toxic microbiology», Social Studies of Science 40(2): 275-306.

Sedgwick, E.K. 2003 Touching Feeling: Affect, Pedagogy, Performativity. Durham, NC: Duke University Press.

Smith, P.A. 2012 «For gastronomists, a go-to microbiologist », New York Times, 19 septembre, Dining D5.

Sommerlund, J. 2006 «Classifying microorganisms: The multiplicity of classifications and research practices in molecular microbial ecology », Social Studies of Science 36(6): 909-928

Standen, A. 2011 «Budding California cheese industry gets grilled by FDA», All things considered, 15 février. [En ligne] : www.npr.org/templates/transcript/transcript. php?storyld=133650263.

Strick, J. 2000 Sparks of Life: Darwinism and the Victorian Debates over Spontaneous Generation. Cambridge, MA: Harvard University Press.

Sutkoski, M. 2012 «The canvases of our landscape», Burlington Free Press.com, 21 octobre. [En ligne] : burlingtonfreepress.com/article/20121020/LIVING20/310200001/ The-canvases-our-landscape?nclick_check=1.

Taussig, K., Høyer, K. \& S. Helmreich 2013 « The anthropology of potentiality in Biomedicine: An introduction », Current Anthropology 54(Suppl. 7): S3-S14.

Teil, G. 2012 « No such thing as terroir? Objectives and the regimes of existence of objects », Science, Technology \& Human Values 37(5): 478-505.

Tenenbaum, D. 2011 «Wisconsin cheese could get boost from "Driftless" label », University of WisconsinMadison New, 4 février. [En ligne] www.news.wisc. $\mathrm{edu} / 18935$

Thompson, C. 2005 Making Parents: The Ontological Choreography of Reproductive Technologies. Cambridge, MA: The MIT Press.

- 2013 Good Science: Ethical Choreography at the End of the Beginning of Stem Cell Research. Cambridge: MIT Press.
Tomes, N. 1999 The Gospel of Germs: Men, Women, and the Microbe in American Life. Cambridge, MA: Harvard University Press.

Toogood, M. 2008 «Beyond "the toad beneath the harrow": Geographies of ecological science, 1959-1965», Journal of Historical Geography 34(1): 118-137.

Trubek, A. 2008 The Taste of Place: A Cultural Journey into Terroir. Berkeley, CA: University of California Press.

Van Heur, B., Leydesdorff, L. \& S. Wyatt 2013 «Turning to ontology in STS? Turning to STS through "ontology" », Social Studies of Science 43(3): 341-362.

Vermeulen, N., Tamminen, S. \& A. Webster 2012 BioObjects: Life in the 21st Century. Ashgate Farnham, Surrey.

Vertesi J. 2012 «Seeing like a Rover: Visualization and embodiment on the Mars exploration rover mission", Social Studies of Science 42(3): 393-414.

Whatmore S. 2002 Hybrid Geographies: Natures Cultures Spaces. Londres: SAGE.

Wilhelm, R.C., Radtke, K.J., Mykytczuk, N.C.S., Greer, C.W. \& L.G. Whyte 2012 «Life at the wedge: The activity and diversity of Arctic ice wedge microbial communities», Astrobiology 12(4): 347-360.

Wilmut, I., Campell, K. C. \& Tudge 2001 The Second Creation: Dolly and the Age of Biological Control. Cambridge, MA: Harvard University Press.

Wolfe, A.J. 2002 «Germs in space: Joshua Lederberg, exobiology, and the public imagination, 1958-1964», Isis 93: 183-205.

Wolfe, B. 2012 «American microbial terroir », Lucky Peach 4: 103-106

Wolfe-Simon, F., Switzer Blum, J., Kulp, T.R., Gordon, G.W., Hoeft, S.E., Pett-Ridge, J. et al. 2010 «A bacterium that can grow by using arsenic instead of phosphorus», Science 332(6034): 1163-1166.

Woolgar, S. \& J. Lezaun 2013 «The wrong bin bag: A turn to ontology in science and technology studies? », Social Studies of Science 43(3): 321-340.

\section{Pour citer l'article}

Paxson, H. \& S. Helmreich 2017 «Périls et promesses de l'abondance microbienne. Natures nouvelles et écosystèmes modèles, du fromage artisanal aux mers extraterrestres », TechniquesE Culture 68 « Mondes infimes », p. 248-285. 